\title{
Ultrasound elastography of the thyroid: principles and current status
}

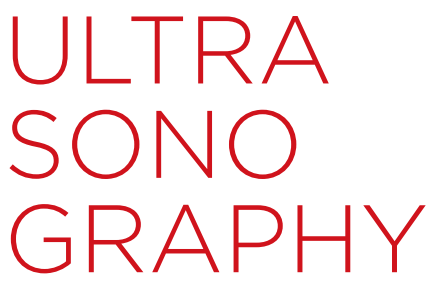

\author{
Chong-Ke Zhao ${ }^{1,2,3}$, Hui-Xiong Xu' ${ }^{1,2,3}$ \\ 'Department of Medical Ultrasound, Shanghai Tenth People's Hospital, Ultrasound Research \\ and Education Institute, Tongji University School of Medicine, Shanghai; ${ }^{2}$ Thyroid Institute, \\ Tongji University School of Medicine, Shanghai; ${ }^{3}$ Shanghai Center for Thyroid Diseases, \\ Shanghai, China
}

\section{REVIEW ARTICLE}

https://doi.org/10.14366/usg. 18037 pISSN: 2288-5919 - elSSN: 2288-5943 Ultrasonography 2019;38:106-124

Received: July 16, 2018

Revised: September 30, 2018

Accepted: October 1, 2018

Correspondence to: Hui-Xiong Xu, MD, PhD, Department of Medical Ultrasound, Shanghai Tenth People's Hospital, Ultrasound Research and Education Institute, Tongji University School of Medicine, 301 Yangchangzhong Rd, Shanghai 200072, China

Tel. +86-21-66307539

Fax. +86-21-66301031

E-mail: xuhuixiong@126.com

\section{Introduction}

Palpation is a practical diagnostic technique, especially for thyroid evaluation, and the presence of a hard thyroid nodule (TN) is associated with an increased risk of malignancy. However, this assessment is subjective and relies on the experience of the examining clinician. Small and deep nodules and those contained in multinodular goiters cannot be palpated reliably. The novel technology of ultrasound (US) elastography has been referred to as "electronic palpation," because it provides a reproducible assessment of tissue consistency. US elastography was first proposed in 1991 by Ophir et al. [1], and was first used for thyroid applications in 2005 by Lyshchik et al. [2]. Moreover, the use of shear-wave elastography (SWE) for diagnosing TNs was first reported in 2010 by Sebag et al. [3]. The stiffness of a tissue is determined by the structural properties of its matrix. Pathological changes, such as the presence of a tumor or inflammation, alter the tissue composition and structure and increase the lesion stiffness [4]. Thus, US elastography can be used to assess the mechanical features of tissue elasticity. However, the pathologies for which elastography is suitable and its mechanisms have not been completely elucidated.

TNs are frequently found and pose a clinical dilemma, because only a few TNs harbor malignancy, while the majority of TNs are benign. The standard work-up of TNs consists of a US examination and fine-needle aspiration (FNA), but both have limitations. In the long-lasting search for suitable

This is an Open Access article distributed under the terms of the Creative Commons Attribution NonCommercial License (http://creativecommons.org/ licenses/by-nc/4.0/) which permits unrestricted noncommercial use, distribution, and reproduction in any medium, provided the original work is properly cited.

Copyright (C) 2019 Korean Society of Ultrasound in Medicine (KSUM)

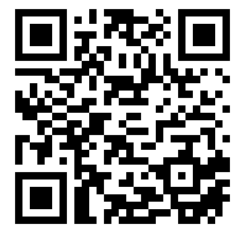

How to cite this article:

Zhao CK, Xu HX. Ultrasound elastography of the thyroid: principles and current status. Ultrasonography. 2019 Apr;38(2):106-124. 
non-invasive diagnostic methods, US elastography has emerged as an additional tool in combination with US and FNA for TN differentiation.

Recently, some authoritative clinical practice guidelines have mentioned US elastography of the thyroid. The 2015 American Thyroid Association (ATA) management guidelines [5] stated that US elastography may be a helpful tool for preoperative accurate risk assessment in patients. Nevertheless, it should not modify the recommendation made based on the gray-scale US evaluation. The 2016 American Association of Clinical Endocrinologists, American College of Endocrinology, and Associazione Medici Endocrinologi Medical (AACE/ACE/AME) guidelines [6] stated that US elastography provides stiffness information, which is complementary to grayscale findings, particularly in nodules with indeterminate US or cytologic characteristics. Moreover, FNA is recommended for nodules with increased stiffness, an intermediate-risk factor. In addition, some specialized guidelines focusing on US elastography have been developed. The 2013 European Federation of Societies for Ultrasound in Medicine and Biology (EFSUMB) guidelines [7] stated that US elastography could be used to guide the follow-up of lesions diagnosed as benign at FNA. In 2017, the World Federation of Societies for Ultrasound in Medicine and Biology (WFSUMB) [4] released a guideline for the use of elastography techniques for the thyroid, with a detailed description of the procedure and its reproducibility, results, and limitations.

To provide a comprehensive overview of the current status of thyroid US elastography, elastography techniques, their clinical applications in various thyroid diseases, diagnostic performance, and influencing factors are reviewed in the present article.

\section{Principles of US Elastography Techniques in the Thyroid}

Depending on which physical quantities are measured, there are two main thyroid elastography methods in clinical practice: strain elastography (SE) and SWE (Fig. 1). They can be classified into different variants based on the excitation method (external force, internal force, and acoustic radiation force [ARF]) and how stiffness is expressed (Fig. 2).

\section{Strain Elastography}

To evaluate the relationship between compression and strain, the Young modulus $(E)$, also known as the ratio of stress $(\sigma)$ to strain $(\varepsilon)$, has been used. $E$ can be calculated using Eq. (1):

$$
E=\frac{\sigma}{\varepsilon},
$$

SE requires mechanical stress, which results in axial displacement of the tissue $[8,9]$. Tissue deformation from the stress is measured and visualized on a screen. The main limitations of SE are operatordependence for the angle, strength, and duration of compression.

Two kinds of elasticity assessments can be obtained by SE. First, a visual scoring system of colors within and around the nodules can be used, with 4- and 5-point elasticity score (ES) systems. Second, two regions of interest (ROIs) are drawn over the target region and an adjacent reference region, respectively. Then, the strain ratio (SR) is automatically calculated [10].

\section{SE with external force}

To acquire elastographic images, free-hand compression is continuously applied by a transducer on the neck, followed by decompression (Fig. 3A) [11,12]. Tissue stiffness is displayed as a

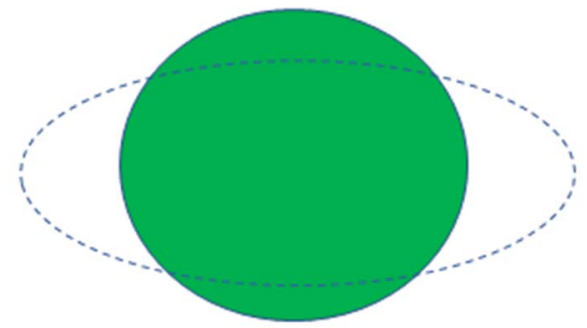

Strain elastography

A
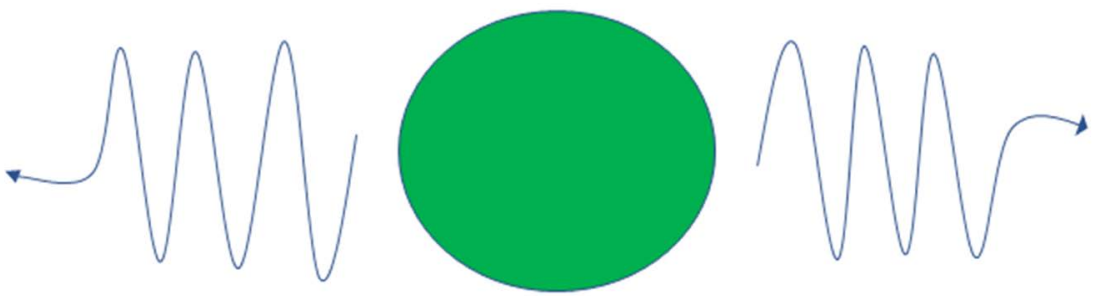

Shear-wave elastography

B

Fig. 1. Principles of strain elastography and shear-wave elastography.

A. Strain elastography assesses tissue elasticity through tissue displacement induced by compression. B. Shear-wave elastography assesses tissue elasticity by measuring the propagation speed of transverse shear waves. 
continuum of colors from red (soft) to green (medium) and blue (hard), although some machines may apply the color scale inversely. The quality of the operator's pressure is monitored by a numeric scale or a sinusoid-shaped curve with a real-time mode (Fig. 4B).
Qualitative assessment: ES

The ES is usually calculated using the 5-point Rago criteria (Fig. 5) [13] or the 4-point Asteria criteria (Fig. 6) [11], based on the predominant color pattern of the nodule. The cut-offs between 3 and 4 on the

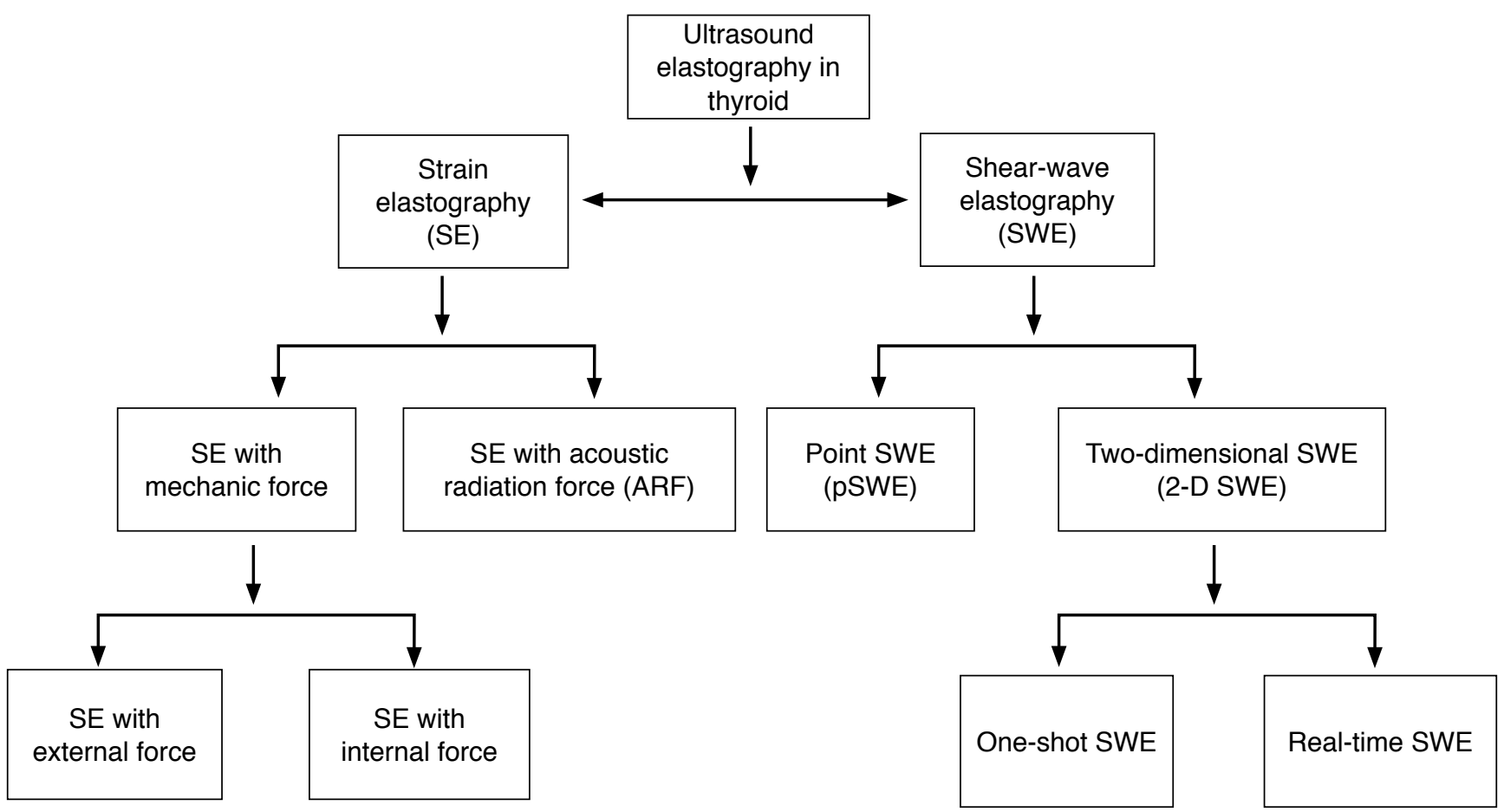

Fig. 2. Classification of ultrasound elastography of the thyroid. Ultrasound elastography of the thyroid can be classified into different variants according to the excitation method and way that stiffness is expressed.

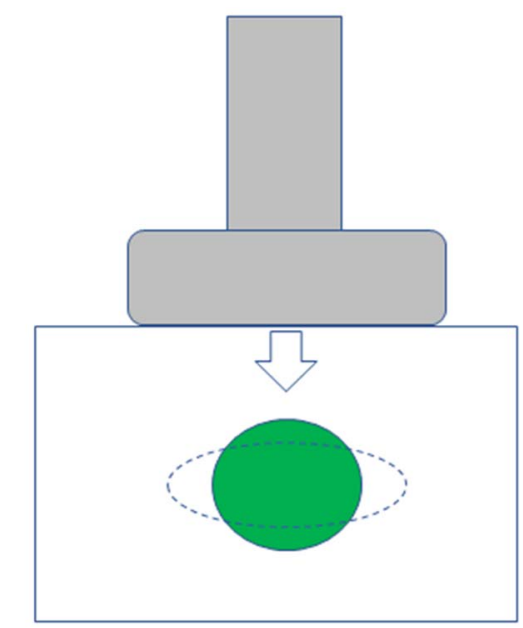

Strain elastography with external force

A

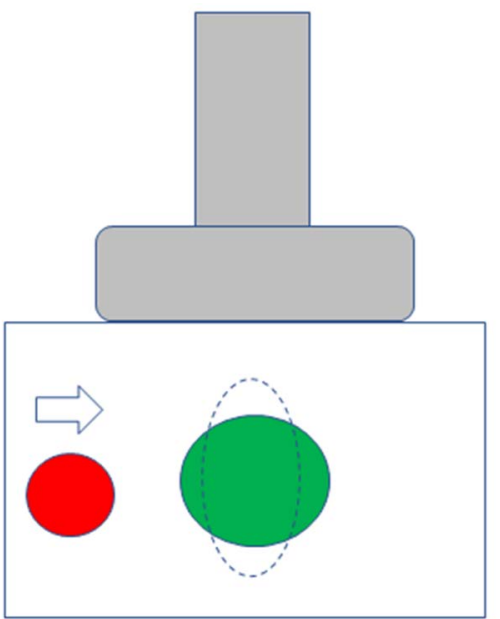

Strain elastography with internal force

B

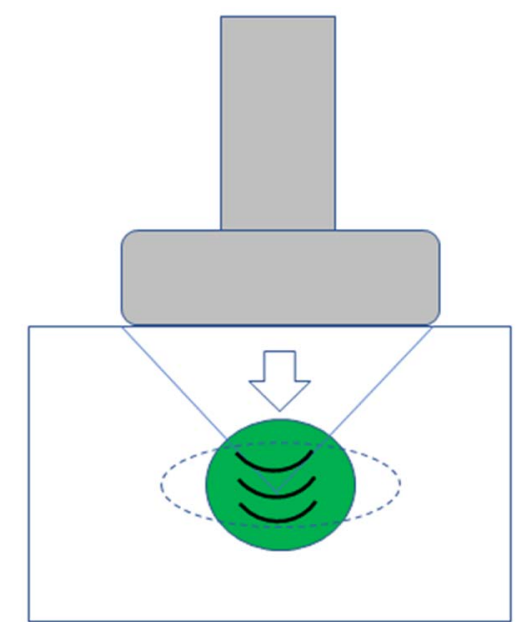

Strain elastography with acoustic radiation force

C

Fig. 3. Principles of different strain elastography techniques using different excitation methods.

A. The elastographic image is acquired through tissue displacement caused by free-hand compression with a transducer. B. The strain image is generated through tissue displacement induced by compression caused by carotid artery pulsation. C. The transducer is used to generate an acoustic radiation force push pulse to excite the target tissue and to monitor the tissue deformation. 
Rago scale and 2 and 3 on the Asteria scale (Fig. 4B) are widely accepted for discriminating benign and malignant nodules.

Semi-quantitative assessment: SR

Second-generation SE devices can display the SR (parenchyma-tonodule or muscle-to-nodule SR [MNSR]). If adjacent normal thyroid tissue is absent, the MNSR can be used. SR does not represent elasticity values, due to the difficulty of measuring the amount of applied stress [14].

\section{SE using carotid artery pulsation}

In this technique, the compression source is carotid artery (CA) pulsation, while the operator holds the probe motionless. Preand post-compression signals are tracked and strain images are

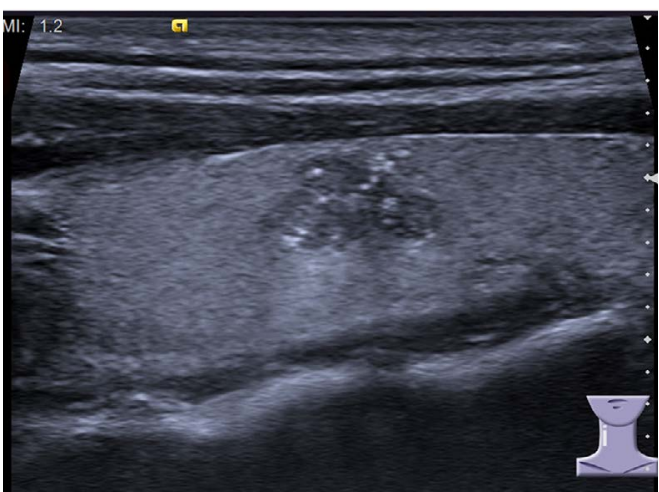

A

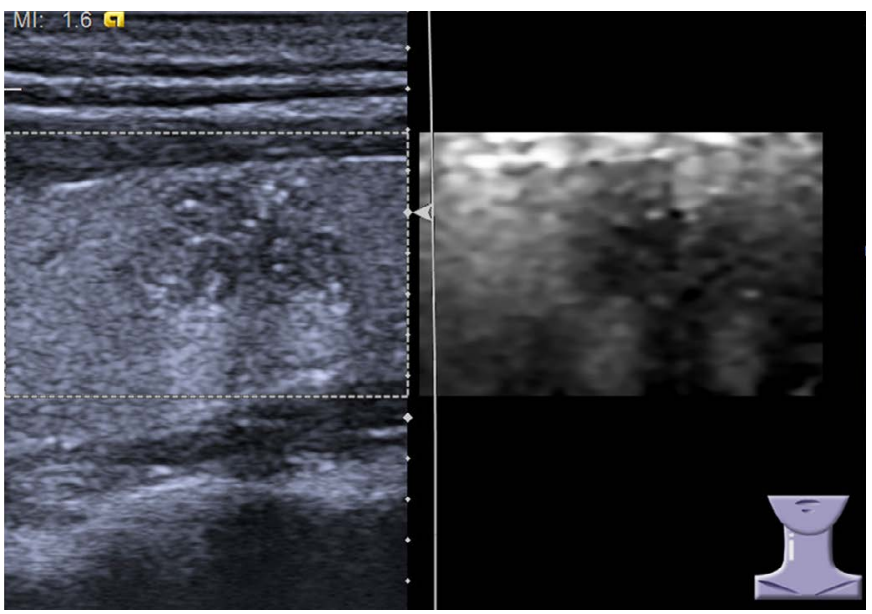

C

B

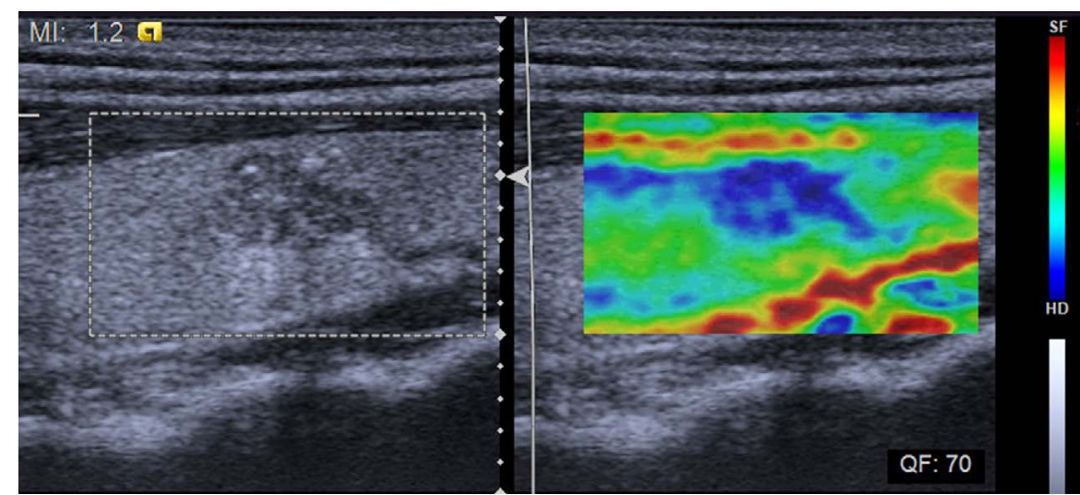

Fig. 4. A 55-year-old man with papillary carcinoma.

A. On gray-scale ultrasonography, a $12-\mathrm{mm}$ thyroid nodule in the right lobe of the thyroid is shown with hypoechogenicity, microcalcification, a poorly defined margin, and irregular appearance. B, C. Elastography displayed an Asteria score of 3 in strain elastography with an external force (with a quality factor of 70) (B), and an acoustic radiation force impulse (ARFI) imaging grade of $\mathrm{V}$ in strain elastography with ARFI imaging (C).

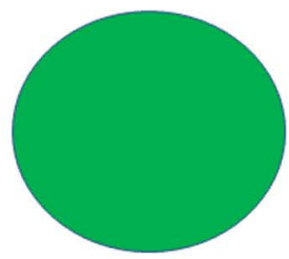

Score 1

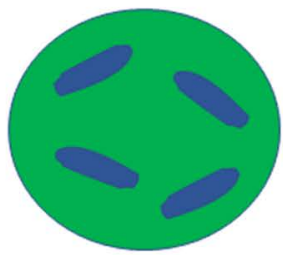

Score 2

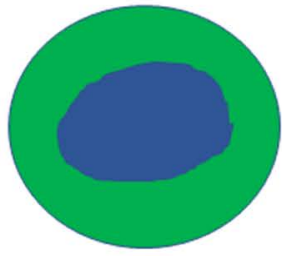

Score 3

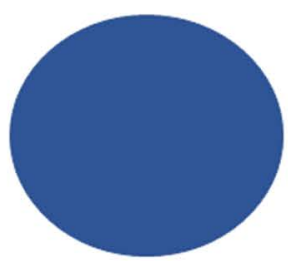

Score 4

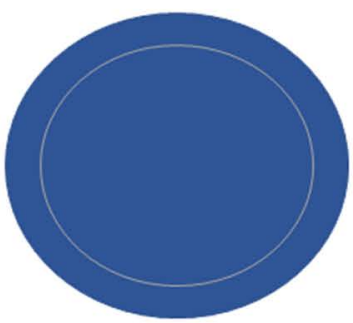

Score 5

Fig. 5. The 5-point Rago criteria for strain elastography of thyroid nodules. A score of 1 indicates even elasticity throughout the whole nodule, a score of 2 indicates elasticity in a large part of the nodule, a score of 3 indicates elasticity only at the peripheral part of the nodule, a score of 4 indicates no elasticity in the nodule, and a score of 5 indicates no elasticity in the nodule or in the area showing posterior shadowing. 


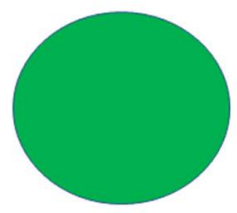

Score 1

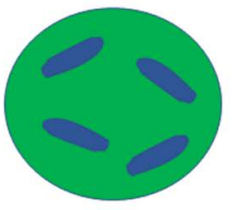

Score 2

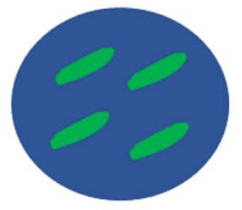

Score 3

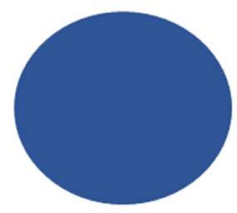

Score 4
Fig. 6. The 4-point Asteria criteria for strain elastography of thyroid nodules. A score of 1 indicates elasticity throughout the entire examined area, a score of 2 indicates elasticity in a large part of the examined area, a score of 3 indicates stiffness in a large part of the examined area, and a score of 4 indicates a nodule without elasticity. generated (Fig. 3B). The hardness is expressed as the thyroid stiffness index (TSI) or the elasticity contrast index (ECI) [10].

\section{Semi-quantitative assessment: TSI}

In this approach, an ROI measuring $2 \times 2 \mathrm{~mm}$ is used on transverse scans, in which both the thyroid and the CA are seen. The strain near the CA (the highest-strain area) is divided by the strain of the TN (the lowest-strain area). A stiff nodule yields a high index value [15].

\section{Semi-quantitative assessment: $\mathrm{ECI}$}

In this approach, a strain oscillation map is obtained. By applying a co-occurrence matrix, the $\mathrm{ECl}$ is computed. Malignant TNs display high contrast, while benign TNs have no or low contrast $[16,17]$.

\section{SE with ARF}

A method known as acoustic radiation force impulse (ARFI) imaging can image tissue deformation using focused US beams (Fig. 3C). Imaging pulses before and after application of focused ARF "push" pulses are used to monitor tissue displacement (as a measure of deformation) within the region of the push. The ARF is calculated using Eq. (2):

$$
F=\frac{2 a l}{c},
$$

where $F$ is the ARF, $\boldsymbol{a}$ is the acoustic absorption, $/$ is the average temporal intensity of the acoustic beam, and $c$ is the speed of sound. The same transducer is used to generate the push pulse and to monitor the resulting tissue displacement. Strain changes are displayed as a gray-scale image. A bright shade indicates relatively soft tissue, whereas a darker shade indicates relatively stiff tissue (Fig. 4C) $[18,19]$.

\section{Qualitative assessment: ES}

A 6-point scale developed by Xu et al. [19] is used for ARFI imaging (Fig. 7) based on the predominant color pattern of the lesion. A cutoff between 3 and 4 is widely accepted to discriminate benign from malignant nodules (Fig. 4C).

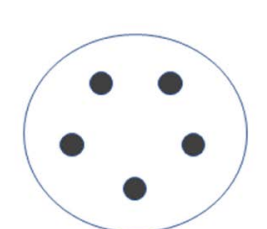

Grade I

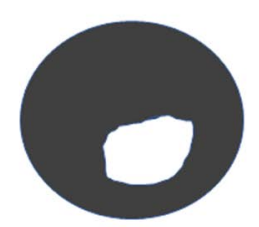

Grade IV

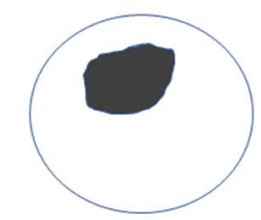

Grade II

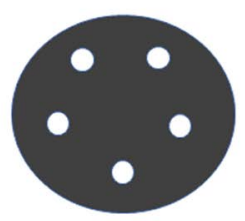

Grade V

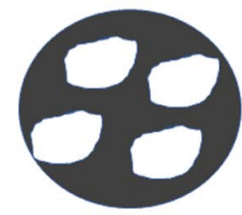

Grade III

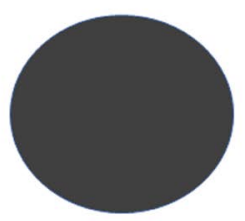

Grade VI
Fig. 7. Acoustic radiation force impulse imaging grades (I-VI) for strain elastography of thyroid nodules. Grade I, the lesion is displayed homogeneously in white or with a few point-like areas of black; grade II, almost the whole lesion is displayed in white, with a small amount of black; grade III, the black and white portions in the whole lesion are almost the same; grade IV, almost the whole lesion is displayed in black, with a small amount of white; grade $\mathrm{V}$, the lesion is displayed almost in black, with a few point-like areas of white; grade VI, the whole lesion is displayed homogeneously in black.

Semi-quantitative assessment: area ratio

In ARFI imaging, the area ratio is defined as the area of the TN on ARFI imaging divided by the area on conventional US. This idea is based on the hypothesis that thyroid cancers might have infiltrative margins [20].

\section{Shear-Wave Elastography}

The acoustic pulses from the probe stimulate the target tissue, creating a shear wave (SW) traveling perpendicular to the conventional US waves. SWS are the transverse components of particle displacement that are rapidly attenuated by the tissue (1$10 \mathrm{~m} / \mathrm{sec}$ ). This transverse component is tracked and measured as a numerical value corresponding to the shear-wave speed (SWS). This speed is closely related to the Young modulus formula, in which tissue elasticity can be assessed from the SW propagation speed $[8,9]$. See the following Eq. (3): 


$$
E \approx 3 \mu, \quad \mu=\rho c^{2}, \quad E=3 \rho c^{2},
$$

(3) fixed size, generating localized displacements that induce a lateral

where $E$ is the Young modulus, $\mu$ is the shear modulus, $\rho$ is the tissue density, and $c$ is the SWS. As SWE is dependent on the production of ARF by the probe, it is operator-independent, reproducible, and quantitative.

Two methods can be used for the clinical evaluation of TNs: the point SWE (pSWE) and 2-dimensional (2-D) SWE techniques (Fig. 8).

\section{pSWE}

The pSWE technique uses short-duration (around 262 microseconds) acoustic pulses that mechanically excite the tissue within an ROI of
SW. Although the amplitude of these SWs is minute, they can be detected with multiple laterally positioned US "tracking" beams and can be analyzed with algorithms to reconstruct the SWS by measurement of the time to peak. Elasticity is expressed as meters per second ( $\mathrm{m} / \mathrm{sec}$ ), and a color-coded image is not displayed (Fig. 9) $[21,22]$.

\section{2-D SWE}

In 2-D SWE, a color-coded map of the SWS is displayed in the field of view (FOV) when it is activated. One or more adjustablemeasurement ROIs can then be placed in the FOV [7,8]. 2-D SWE can be performed using the "one-shot" technique or the "real-

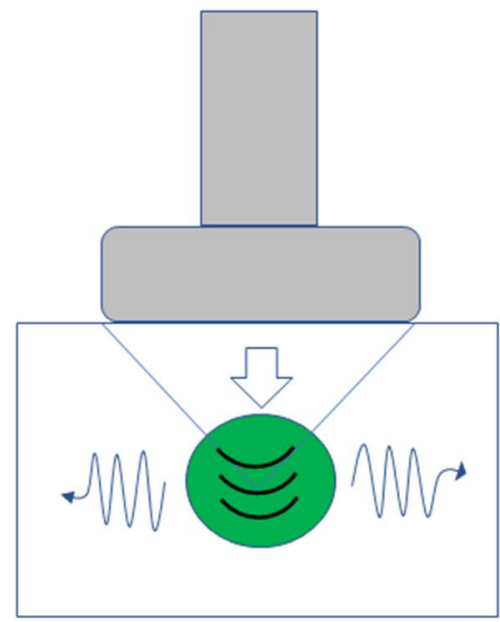

pSWE
A

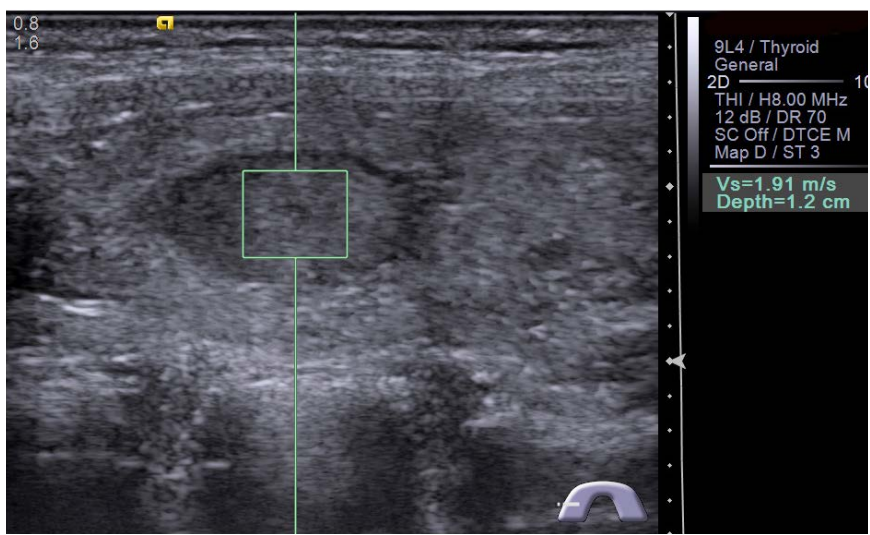

A

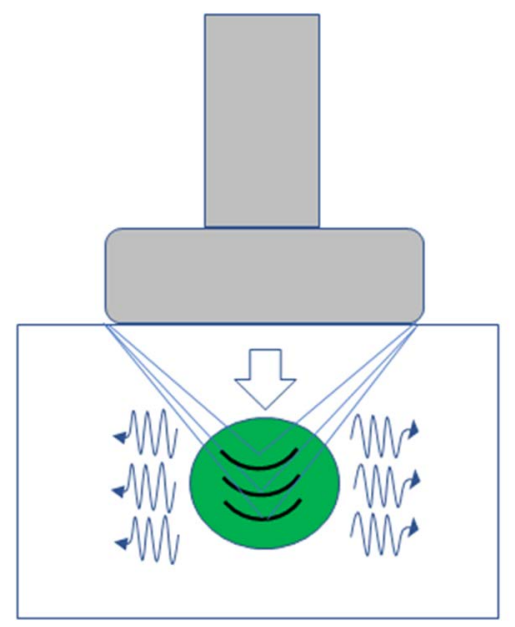

2-D SWE
Fig. 8. Principle of point shear-wave elastography (pSWE) and 2-dimensional shear-wave elastography (2-D SWE).

A. pSWE uses acoustic radiation force (ARF) to mechanically excite the target tissue in a single focal location that creates a lateral shear wave. B. In contrast, 2-D SWE uses ARF beams to generate shear waves in a full field of view.

Fig. 9. Nodular goiter in a 45-year-old woman.

On gray-scale ultrasonography, a solid-component 18-mm thyroid nodule with hypoechogenicity and a well-defined margin in the right lobe is shown. A. A shear-wave speed (SWS) of $1.91 \mathrm{~m} / \mathrm{sec}$ in the nodule is displayed on the Virtual Touch Tissue Quantification (VTQ) system using point shear-wave elastography. B. A SWS of $2.39 \mathrm{~m} / \mathrm{sec}$ in the same depth surrounding the parenchyma is displayed on the VTQ. 
time" technique.

\section{"One-shot" 2-D SWE technique}

The Virtual Touch Tissue Imaging and Quantification (VTIQ, Siemens Medical Systems, Mountain View, (A, USA) system is a representative means of performing the "one-shot" 2-D SWE technique. The VTIQ system can be used to measure the SWS that propagates at a number of locations around the ARFI through a detection pulse. The image is acquired by translating the focus to cover up to 256 acquisition lines within 700 milliseconds (with an elastogram box width of $38 \mathrm{~mm}$ ). Time is needed to allow the transducer to cool before another image can be generated

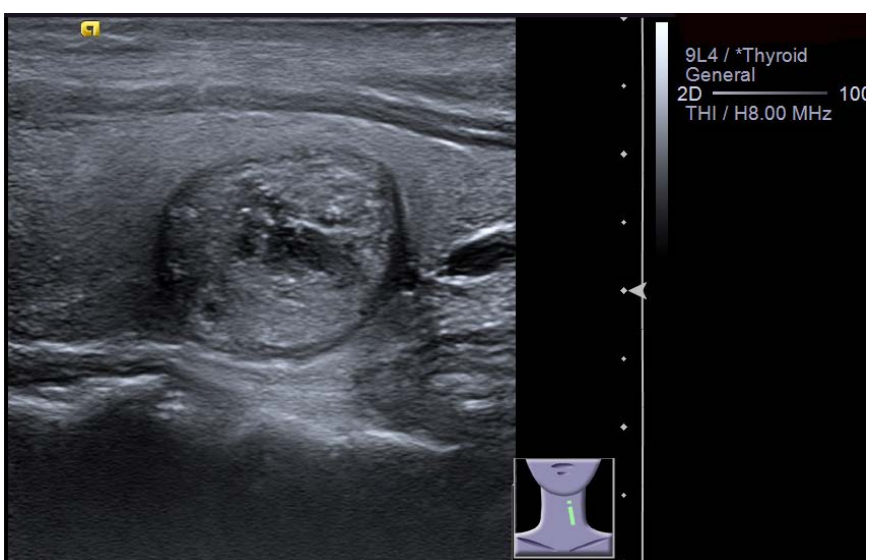

A

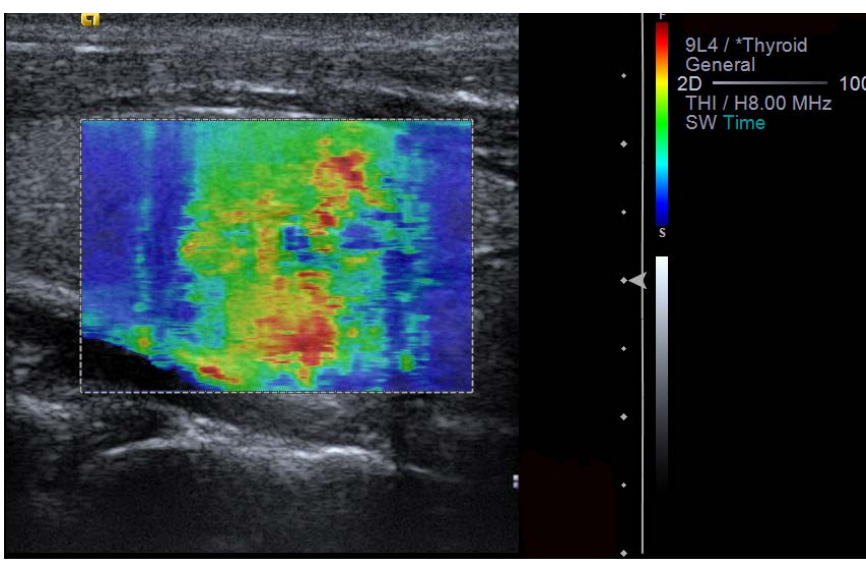

C

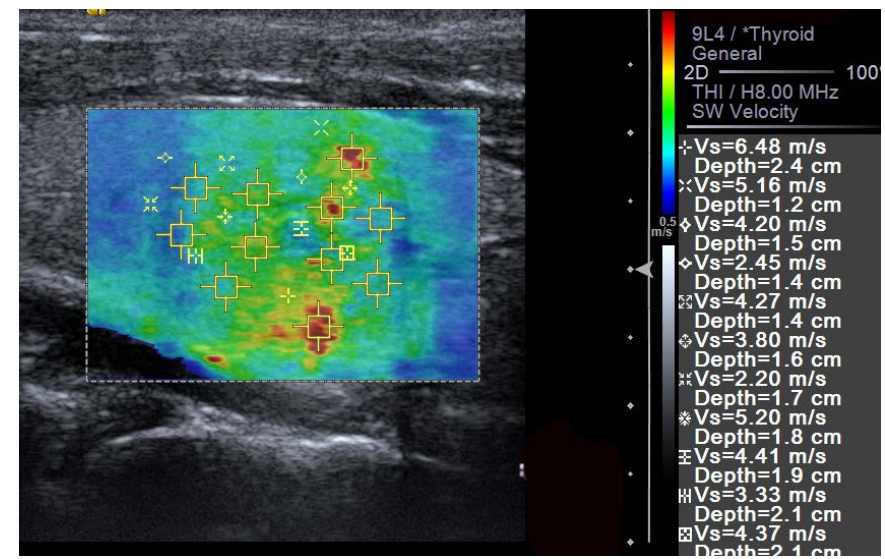

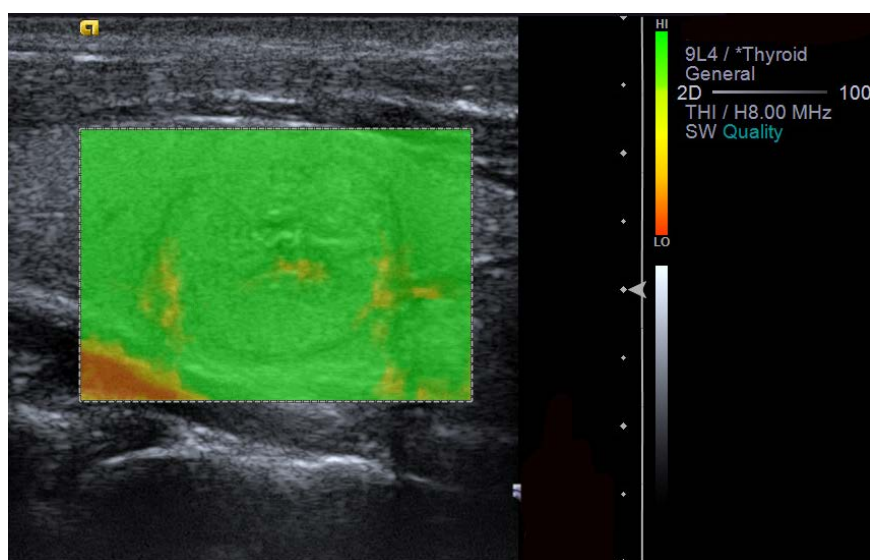

B

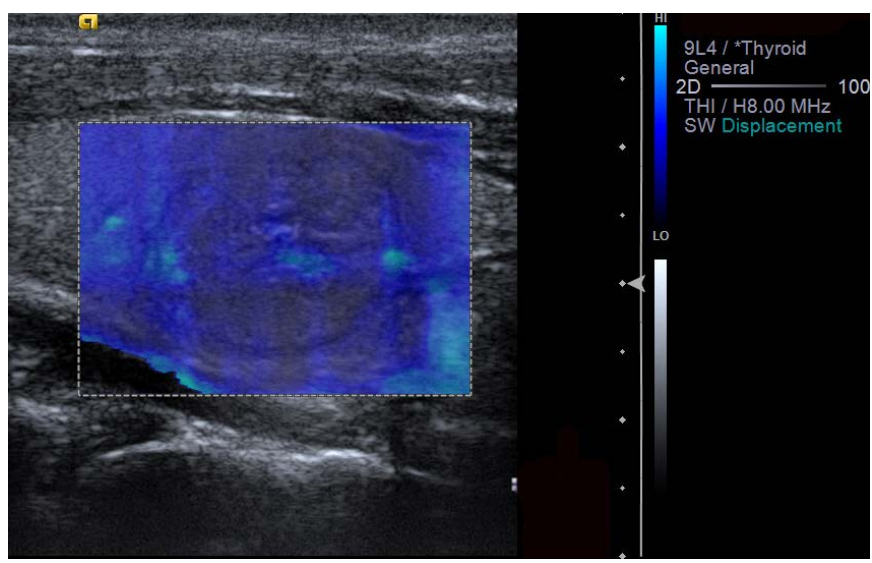

D

Fig. 10. Papillary thyroid carcinoma in a 49-year-old man.

A. On gray-scale ultrasonography, a predominantly solid $19-\mathrm{mm}$ thyroid nodule with isoechogenicity, microcalcifications, and welldefined margin in the left lobe is shown. Four modes are displayed in the Virtual Touch Tissue Imaging and Quantification system. B. On the shear wave quality map, the nodule shows good-quality shear wave propagation. C, D. The shear wave time map (C) and shear wave displacement map (D) are obtained. E. The shear wave velocity map shows the nodule to have a mean SWS value of $4.17 \mathrm{~m} / \mathrm{sec}$, ranging from 2.45 to $6.48 \mathrm{~m} / \mathrm{sec}$. 


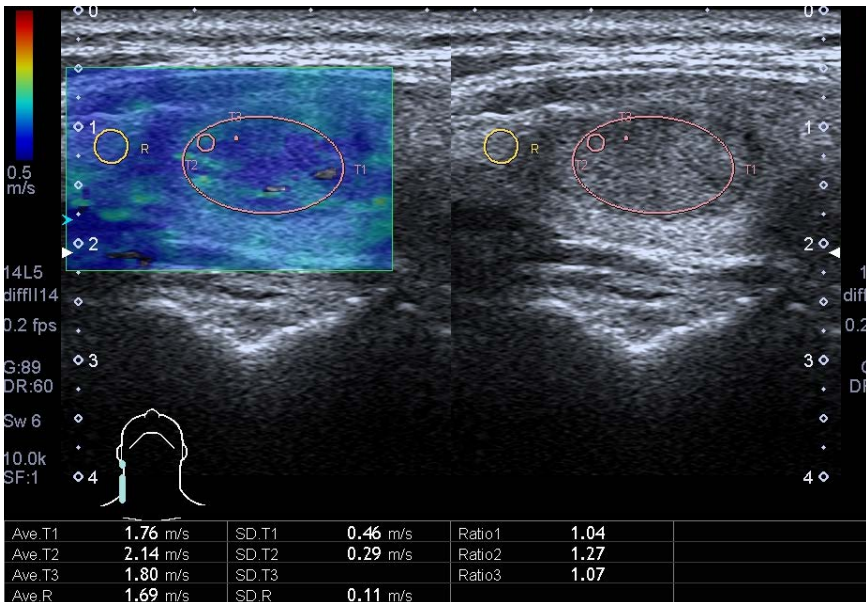

A

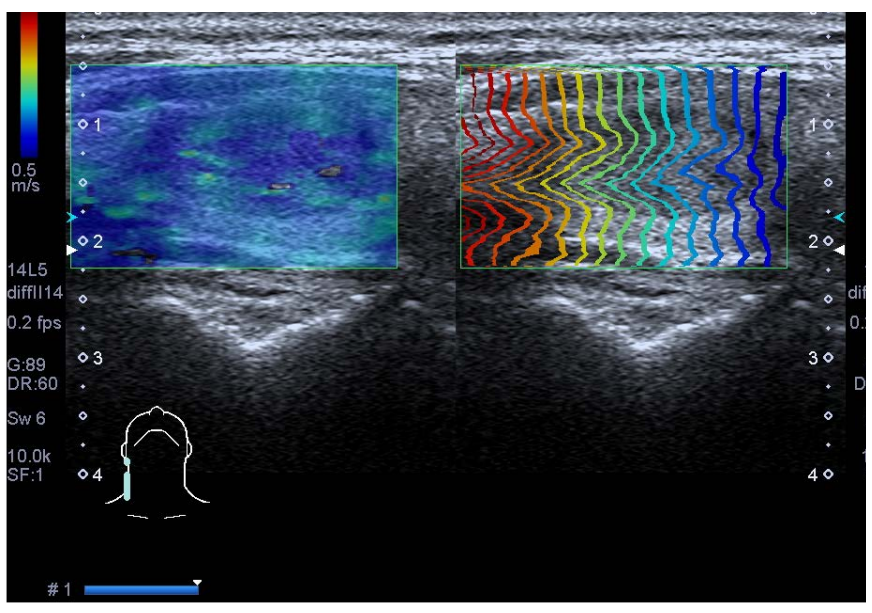

C

after acquiring an image. Compared with PSWE, VTIQ provides more precise stiffness information within TNs because of its 2-D visualization of the SWS distribution in various colors and smaller SW ROIs. A SW-quality map is available to evaluate whether SWS propagation is reliable or adequate (Fig. 10) $[23,24]$.

The 2-D SWE technique can also be performed using a Toshiba US system (T-SWE, Toshiba Medical System, Tochigi, Japan), which uses SWs to interrogate the viscoelastic properties of tissues. These SW display maps can be viewed in a "real-time" mode; however, a higher-quality "one-shot" mode is chosen for quantitative analysis. Its unique propagation map uses contour lines to depict SW arrival times at different points in the tissue. It is designed to allow operators to better assess the suitability of one-shot acquisitions and to optimize ROI placement such that the SW ROI is generally placed on areas with parallel contour lines (Fig. 11) [25,26].

\section{"Real-time" 2-D SWE technique}

SuperSonic SWE (S-SWE; SuperSonic Imagine [SSI], Aix-en-Provence,

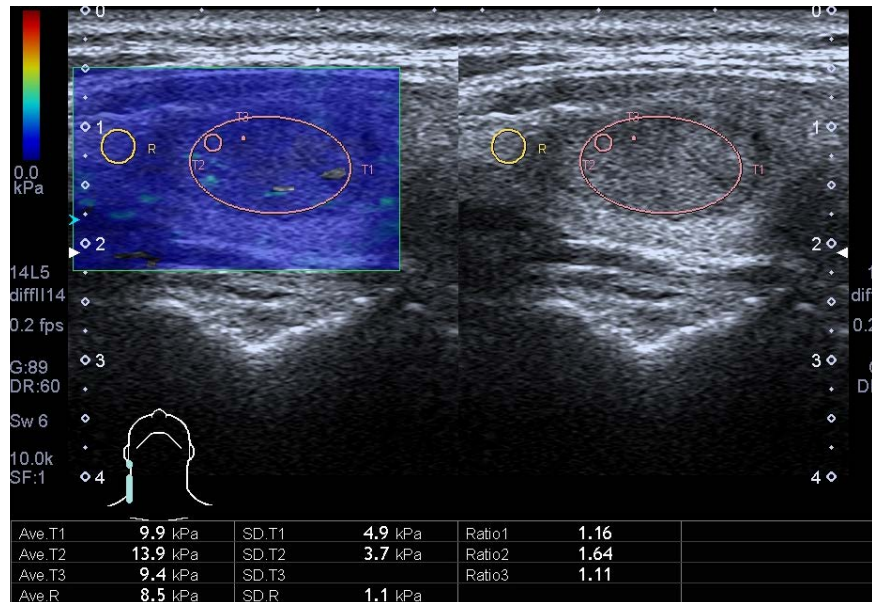

B

Fig. 11. A 55-year-old woman with a fine-needle aspirationproven benign thyroid nodule.

The solid isoechogenic $21-\mathrm{mm}$ nodule located on the right is shown on a gray-scale ultrasound image. Three display modes are displayed on Toshiba shear-wave elastography. A. In the shear wave velocity mode, indices of an Emean of $1.76 \mathrm{~m} / \mathrm{sec}, E_{\mathrm{SD}}$ of $0.46 \mathrm{~m} / \mathrm{sec}$, and Emax of $2.14 \mathrm{~m} / \mathrm{sec}$ are obtained. B. In the shear wave elasticity mode, indices of Emean of $9.9 \mathrm{kPa}, E_{S D}$ of $4.9 \mathrm{kPa}$, and Emax of $13.9 \mathrm{kPa}$ are obtained. C. Propagation (arrival time contour) mode is shown.

France) uses focused ultrasonic beams (so-called pushing beams) that propagate through the entire imaging area, and ultrafast US is used to measure the velocity of the induced SWs. From these data, tissue elasticity can be quantitatively estimated. The stiffness of a particular ROI, including mean stiffness (Emean), maximal stiffness (Emax), and standard deviation, can be expressed as SWS (m/sec) or elasticity ( $\mathrm{kPa}$ ). Soft tissue is displayed in blue and hard tissue is displayed in red (Fig. 12) [27,28].

The comb-push ultrasound shear elastography (CUSE; GE Healthcare, Wauwatosa, WI, USA) device is used to apply a recently developed technique in which multiple simultaneous laterally-spaced ARF beams generate a full FOV with SWs travelling in both lateral directions. CUSE is less affected by significant SW attenuation in areas that are far from the push beam, making it more reliable and accurate for measurements of SWS. More importantly, a full FOV reconstruction of the SWS map can be obtained with only a single fast data acquisition (about 25 milliseconds). CUSE can play an important role in thyroid applications since interference from carotid pulsation (about 
1-2 pulses per second) can be avoided (Fig. 13) $[29,30]$.

Three-dimensional (3-D) SWE is a more recent development. Highresolution 3-D SWE images can be acquired using a 3-D volumetric probe (SSI) that provides 3-D elasticity maps of the entire TN and surrounding tissue $[8,31]$.

\section{Practical Clinical Applications}

\section{Diagnostic Performance for Thyroid Malignancy}

US is highly sensitive for detecting TNs and good for characterizing TNs. However, no single US feature or combination thereof can reliably predict thyroid malignancy.

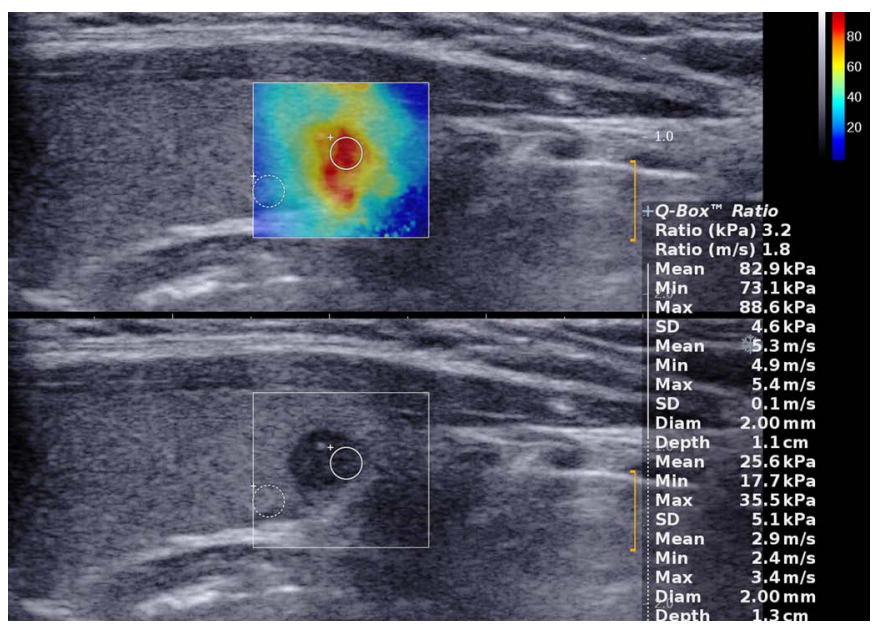

Fig. 12. Papillary thyroid carcinoma in a 28-year-old woman. Grayscale ultrasonography (lower side) shows a solid hypoechoic 6-mm thyroid nodule with poor margin and microcalcifications. SuperSonic shear-wave elastography (upper side) shows a heterogeneously stiff (red and yellow) nodule with a maximum elasticity of $88.6 \mathrm{kPa}$.

\section{Diagnostic performance of elastography and the combination of elastography and conventional US}

The main studies that have investigated the diagnostic performance of US elastography, including meta-analyses, are listed in Table 1 $[3,19,22,23,27,28,31-46]$. A meta-analysis including 639 TNs found SE to be useful for the assessment of malignancy, with an overall mean sensitivity of $92 \%$ and mean specificity of $90 \%$ [47]. A meta-analysis of the SR method demonstrated a pooled sensitivity and specificity of $85 \%$ and $80 \%$, respectively [35]. The prospective DEGUM multicenter study, which enrolled 602 patients with 657 TNs (567 benign, 90 malignant) from seven centers, found that SE as an additional US tool improved the value of US for the work-up of TNs [33]. A meta-analysis of 15 studies of SWE that included 1,867 TNs demonstrated that the pooled sensitivity and specificity of SWE were $84.3 \%$ and $88.4 \%$, respectively [34]. However, these findings were challenged by the results of a retrospective study of 703 nodules reporting that the sensitivity of SE measurements (15.7\% for the 5-point Rago criteria, $65.4 \%$ for the 4-point Asteria criteria) was less than that of gray-scale US features (91.7\%) [36].

In real clinical practice, US elastography is usually performed as an extension of conventional US and not as an independent test. This is supported by the results of Trimboli et al. [12], who reported that the combination of these two modalities resulted in a sensitivity of $97 \%$ and negative predictive value (NPV) of $97 \%$, which was higher than using the TSI of SE alone or B-mode features alone. Most reports have stated that a combination of conventional US and elastography showed higher sensitivity than conventional US alone. In contrast, the diagnostic accuracy, specificity, and positive predictive value (PPV) were inferior to those of conventional US alone. Moon et al. [36] found that neither elastography nor the combination of elastography and gray-scale US showed better performance for

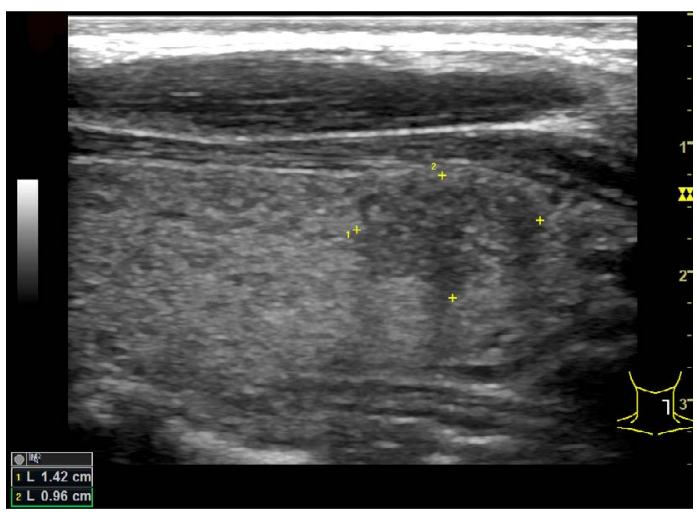

A

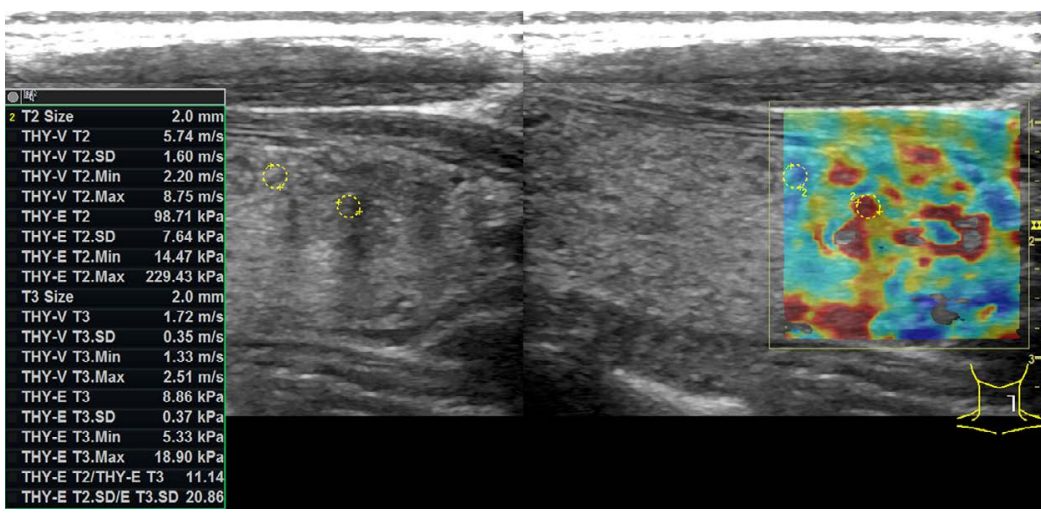

B

Fig. 13. Papillary thyroid carcinoma in a 40-year-old woman.

A. Gray-scale ultrasonography shows a solid hypoechoic 14-mm nodule with a poor margin and microcalcifications. B. The comb-push ultrasound shear elastography system shows a heterogeneously stiff (red and yellow) nodule with a maximum elasticity of $229.43 \mathrm{kPa}$. 
diagnosing thyroid cancers than gray-scale US. Therefore, the clinical application of US elastography should be determined based on how much experience the operator has with both conventional US and elastography for the thyroid.

Table 1. The main studies evaluating the diagnostic performance of elastography in differentiating benign and malignant thyroid nodules

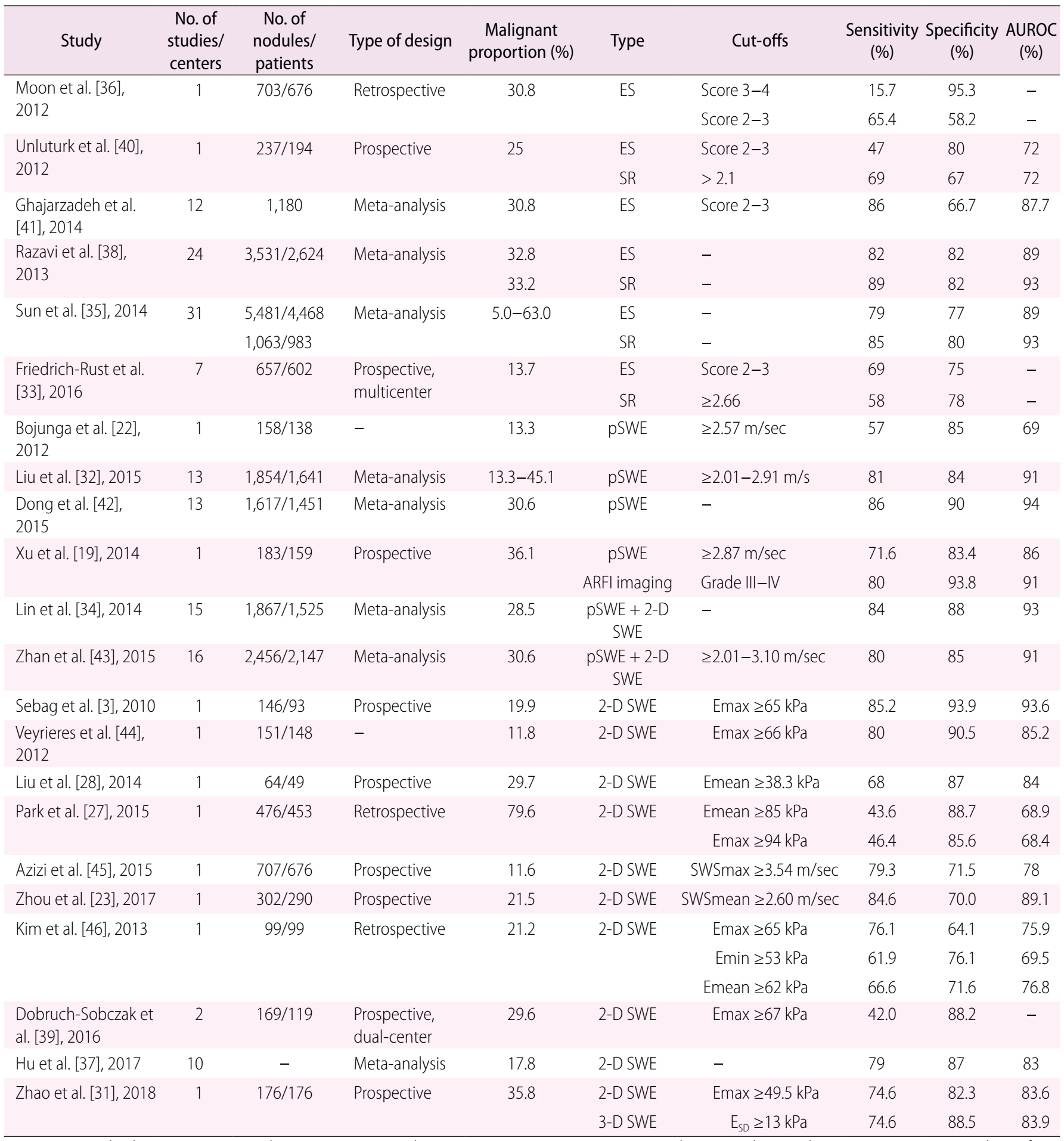

AUROC, area under the receiver operating characteristic curve; ES, elasticity score; SR, strain ratio; pSWE, point shear-wave elastography; ARFI imaging, acoustic radiation force impulse imaging; 2-D SWE, 2-dimensional shear-wave elastography; 3-D SWE, 3-dimensional shear-wave elastography. 


\section{Diagnosis of papillary thyroid microcarcinoma}

Some studies have reported that SE could help to differentiate between benign and malignant thyroid micronodules $[48,49]$. Ma et al. [50] conducted a study to preoperatively predict papillary thyroid microcarcinoma (PTMC) via multiparameter US, finding that conventional US combined with contrast-enhanced US and SE could improve the diagnostic accuracy of PTMC. Zhang et al. [51,52] found that PSWE had a higher specificity than conventional US in diagnosing malignant TNs, particularly PTMCs. Thus, pSWE could increase the diagnostic confidence of the readers. A study indicated that the quantitative indices of 2-D SWE were independent predictive factors for diagnosing PTMC, which provided valuable information when conventional US could not give determinate results [53]. One study referred to the value of 2-D SWE in differentiating PTMC, as the majority of the PTMCs (5 of 9) were missed by 2-D SWE [28].

\section{Differentiation of nodules with coexistent Hashimoto thyroiditis}

Thyroid parenchymal stiffness is increased in patients with Hashimoto thyroiditis (HT) [54], but whether inflammation reduces the accuracy of elastography in nodule evaluation is still a matter of debate [55]. SWE seemed to correctly define the elasticity of TNs independently from the coexistence of HT [56]. For the differentiation of true nodules from pseudonodules, SE had a sensitivity of $92.9 \%$, a specificity of $95 \%$, a PPV and NPV of $86.7 \%$ and $97.4 \%$, respectively, and an accuracy of $94.4 \%$, which was better than the combination of gray-scale and Doppler US [57]. SR proved to be slightly better than ES for the diagnosis of nodules in this disease [58]. Liu et al. [59] reported that ARFI elastography was useful for predicting thyroid malignancy in HT patients, and its diagnostic performance was better than that of SE.

\section{Role of US Elastography in Reducing Unnecessary FNAs}

In order to reduce the number of unnecessary FNAs, US elastography plays a major role in determining which nodules can be followed with imaging without FNA, with a high NPV [12]. The use of the TSI of SE might reduce the number of punctures by $60.8 \%$ [60] while the concomitant application of the Thyroid Imaging Reporting and Data System (TI-RADS) system and elastography might reduce the number of FNAs by 33.8\% [61]. Zhao et al. [31] reported that for the 37 nodules with low suspicion on conventional US imaging, 2-D SWE was able to avoid unnecessary FNA in $77.1 \%$ of benign nodules, and 3-D SWE further increased the number to $88.6 \%$.

\section{Recommendations for Surgery}

All the meta-analyses concluded that SWE (pSWE and 2-D SWE) is a useful complement to conventional US in predicting thyroid malignancy. It was concluded that SWE can be useful in selecting patients with TNs for surgery [43].

\section{Diagnostic Utility in TNs with Nondiagnostic or Indeterminate Cytology}

US-guided FNA is the widely accepted next step for diagnosing TNs, as it is relatively noninvasive and shows excellent performance. Nevertheless, FNA cytology is far from being a gold standard, because it has major limitations in excluding malignancy in lesions with nondiagnostic or indeterminate cytology. Several approaches have been used to overcome these limitations, such as repeated FNA, molecular testing, and intraoperative frozen sections. However, repeating FNA and performing molecular testing both require additional costs, and intraoperative frozen sections are by definition not performed preoperatively [62]. Preliminary results are mixed about the role of elastography in TNs with nondiagnostic or indeterminate cytology [63-70].

\section{Diagnostic utility in TNs with nondiagnostic cytology}

Although two studies have reported US elastography to be valuable in TNs with nondiagnostic cytology $[63,64]$, conventional US also displayed good diagnostic performance. Lin et al. [71] proposed an effective predictive model including elastography for identifying malignant TNs in patients with nondiagnostic cytologic findings. Park et al. [72] proposed that observation might be considered for solid TNs with nondiagnostic cytology that have no other suspicious US features and are benign on SE using the Asteria criteria.

\section{Diagnostic utility in TNs with indeterminate cytology}

Some studies have confirmed the usefulness of qualitative and quantitative $S E$ to predict thyroid malignancy $[64,65]$. However, the study of Lippolis et al. [66] did not confirm the usefulness of SE in the presurgical assessment of TNs with indeterminate cytology. A meta-analysis of eight studies with 486 indeterminate-cytology TNs demonstrated pooled sensitivity, specificity, and accuracy of $69 \%$, $75 \%$, and $73 \%$, respectively, for SE [67].

Samir et al. [68] reported that a higher median Young modulus from the transverse plane in SWE was associated with malignancy, with an area under the curve (AUC) of 0.81 for predicting malignancy in a study of 35 patients with indeterminate follicular TNs. A preliminary study indicated that VTIQ and the Afirma gene expression classifier demonstrated similar diagnostic performance and were independent predictors of malignancy in TNs with Bethesda III/IV results [69]. Bardet et al. [70] conducted a prospective dual-center study including surgically proven TNs $\geq 15$ $\mathrm{mm}$ with Bethesda III-V results. The SWE parameters were similar 
between benign and malignant nodules. The SWE indices failed to predict malignancy in TNs with indeterminate cytology.

Overall, $10 \%-75 \%$ of indeterminate-cytology nodules are follicular neoplasms [73]. SWE may be helpful in defining the extent of thyroidectomy (total or lobectomy) for follicular neoplasms [74]. More importantly, the incidence, risk of malignancy, and clinical significance are different among each category of indeterminate cytology, including Bethesda categories III, IV, and V. Thus, it is necessary to evaluate the value of US elastography in each category of indeterminate cytology in future studies.

\section{Prediction of Cervical Lymph Node Metastasis in Patients with Papillary Thyroid Cancer}

Cervical lymph node (CLN) metastasis is associated with increased local recurrence and decreased survival in some high-risk groups. However, CLN microscopic metastases with false-negative US characteristics have been reported in up to $90 \%$ of papillary thyroid cancer (PTC) cases associated with CLN metastasis. The risk of permanent hypoparathyroidism and permanent recurrent laryngeal nerve injury is higher for thyroidectomy accompanied with CLN dissection than for total thyroidectomy alone. Thus, a reliable assessment of CLN status is important in the treatment planning and prognostic evaluation of PTC patients.

It has been reported that US elastography was helpful for predicting CLN metastasis. Xu et al. [75] preoperatively evaluated a consecutive series of 203 patients with 222 PTCs by US, SE, and ARFI elastography including ARFI imaging and pSWE. Using a combination of US characteristics with and without ARFI imaging, the AUC, sensitivity, and specificity were 0.803 and $0.556,83.0 \%$ and $100 \%$, and $77.6 \%$ and $11.2 \%$, respectively $(P<0.001)$. Thus, ARFI elastography showed superior performance over conventional US, particularly when combined with conventional US, in predicting CLN metastasis in PTC patients. Park et al. [76] retrospectively analyzed 363 patients with 363 PTCs who underwent preoperative SWE evaluations. The findings showed that Emean and Emax was associated with central lymph node (LN) metastasis and Emin was associated with lateral LN metastasis. The quantitative elasticity index of PTC on preoperative SWE in combination with gray-scale US findings might be useful for predicting CLN metastasis. However, Yoon et al. [77] reported that none of the histogram parameters on SE had significant associations with poor prognostic factors, including LN metastasis.

\section{Diffuse Thyroid Diseases and Thyroiditis}

\section{Diffuse thyroid diseases}

In general, HT and Graves disease (GD) are diagnosed according to clinical, laboratory, and US findings. Sporea et al. [78] reported that there were significant differences in pSWE between normal subjects and patients with diffuse thyroid disease (GD and HT pathology), with SWS values of $2.07 \pm 0.44 \mathrm{~m} / \mathrm{sec}$ versus $2.68 \pm 0.50 \mathrm{~m} / \mathrm{sec}$, respectively. They suggested that pSWE could predict the presence of diffuse thyroid disease with sufficient diagnostic accuracy (AUC, 0.804). However, no significant difference was found between GD and $\mathrm{HT}(2.82 \pm 0.47 \mathrm{~m} / \mathrm{sec}$ vs. $2.49 \pm 0.48 \mathrm{~m} / \mathrm{sec})$. pSWE seems to be unsuitable for differentiating GD and HT. Liu et al. [79] also found that SWE failed to differentiate HT from GD. Fukuhara et al. [80] found that the SWS in patients with HT $(2.47 \pm 0.57 \mathrm{~m} / \mathrm{sec})$ was significantly higher than that in controls $(1.59 \pm 0.41 \mathrm{~m} / \mathrm{sec})$. The AUC for HT was 0.92 , and the cut-off SWS value was $1.96 \mathrm{~m} / \mathrm{sec}$. The sensitivity, specificity, and diagnostic accuracy were $90.6 \%$, $78.7 \%$, and $85.1 \%$, respectively. Therefore, pSWE may be useful for diagnosing $\mathrm{HT}$ and assessing the degree of fibrosis in HT.

\section{Subacute thyroiditis}

Subacute thyroiditis (SAT) is a self-limiting inflammatory process. Most patients have a history of upper respiratory tract infection and pain in the neck. On US, SAT appears as an enlargement of the affected thyroid and poorly defined focal areas of hypoechogenicity with hypovascularity. A study documented a significant difference in the stiffness of thyroid hypoechoic lesions in 18 patients with SAT between baseline (214.26 $\pm 32.5 \mathrm{kPa}$, with 17 [94.4\%] with an ES of IV and 1 [5.6\%] with an ES of III) and at a 10-week follow-up visit after treatment $(21.65 \pm 5.3 \mathrm{kPa}$, with 15 [83.3\%] with an ES of I and 3 [16.7\%] with an ES of II) [54]. SAT also showed greater hardness than $\mathrm{HT}$ according to an SR evaluation [81]. The ES may help to differentiate between SAT and multinodular goiter, but it is not sufficient for distinguishing SAT from thyroid cancer, due to the similarity in the degree of stiffness [82].

\section{Acute thyroiditis}

Acute thyroiditis (AT) is a rare condition often caused by bacterial infection. The US characteristics of AT are an ill-defined lesion with heterogeneous hypoechogenicity. Ruchala et al. [54] reported that the thyroid tissue stiffness in two women with AT was $216.6 \mathrm{kPa}$ and $241.9 \mathrm{kPa}$, respectively (both with an ES of IV). After treatment, thyroid stiffness decreased to $17.93 \mathrm{kPa}$ (an ES of I) and 85.348 $\mathrm{kPa}$ (an ES of II), respectively. Thus, elastography may be useful for monitoring the course of AT.

\section{Riedel thyroiditis}

Riedel (chronic) thyroiditis is characterized by extremely stiff parenchyma. The hypoechoic areas are the stiffest, representing fibrosis. Slman et al. [83] obtained stiffness values of $143 \mathrm{kPa}$ and 
$281 \mathrm{kPa}$ by SWE in two female patients with Riedel thyroiditis.

\section{Comparison of Different Elastography Methods}

Various commercially available US elastography devices are available from different manufacturers, with corresponding variation in techniques; thus, there is a growing need to understand their principles and to compare their real-world clinical impact.

\section{Comparisons between Different SE Evaluation Methods}

A study compared SE based on 4-point ES and the SR between the nodule and the surrounding thyroid at the same depth [84]. The diagnostic accuracy of the SR evaluation was clearly higher than that of the ES (0.88 vs. 0.79 ), as was the specificity.

\section{Comparison between SE and SWE}

The ability of 2-D SWE and 5-point ES in SE to discriminate 64 TNs (19 PTCs and 45 benign) in 49 patients was compared. In that study, Liu et al. [28] concluded that SWE is a promising tool for differentiating TNs, as the best cut-off of a mean value of 38.3 $\mathrm{kPa}$ yielded results comparable to those of $\mathrm{SE}$, with slightly lower sensitivity and slightly higher specificity.

In another study with 158 nodules in 138 patients, Bojunga et al. [22] found that there was no significant difference in diagnostic accuracy for the diagnosis of malignant TNs between PSWE and 4-point ES in SE (0.69 vs. 0.74), and the combination of pSWE and SE did not improve the diagnostic accuracy.

\section{Comparisons of Different SWE Techniques}

Yang et al. [85] first compared VTIQ for 2-D SWE and the Virtual Touch Tissue Quantification system (VTQ, Siemens Medical Systems) for pSWE for the diagnosis of 107 TNs in 107 patients. VTIQ and VTQ were equivalent in diagnosing TNs when using SWS-mean, whereas VTIQ showed better performance than VTQ when using SWS-median.

He et al. [25] reported the first comparison of VTIQ and T-SWE in the diagnosis of TNs. In general, VTIQ was equivalent to T-SWE for diagnosing TNs. In clinical practice, the selection of SWS-max should be avoided in VTIQ, whereas it should be applied in T-SWE.

He et al. [26] also performed the first evaluation of two different 2-D SWE imaging systems (T-SWE and S-SWE), and compared their ability to distinguish malignant from benign TNs. Their study found that T-SWE was equivalent to S-SWE, with comparable and promising results for the diagnosis of TNs. In clinical applications, the selection of Emax should be recommended, both for T-SWE and for S-SWE.

\section{Influencing Factors}

\section{Nodule Features}

\section{Nodules with calcifications and cystic changes}

Elastography cannot be performed on nodules with a calcified shell because the sound waves cannot penetrate the calcifications [13]. Intralesional coarse calcifications may bias the stiffness of the lesion, as can peripheral calcifications $[11,86]$. A partially cystic character is expected to alter nodule elasticity, although the direction of this

Table 2. Inter-observer and intra-observer variability of elastography

\begin{tabular}{|c|c|c|c|c|c|}
\hline Study & Type & No. of nodules & Statistical method & $\begin{array}{l}\text { Inter-observer } \\
\text { statistical value }\end{array}$ & $\begin{array}{l}\text { Intra-observer } \\
\text { statistical value }\end{array}$ \\
\hline Park et al. [90], 2009 & ES & 52 & Spearman correlation coefficient & $0.08-0.22$ & - \\
\hline Ragazzoni et al. [87], 2012 & ES & 132 & Cohen kappa statistic & 0.64 & - \\
\hline Kim et al. [92], 2012 & ES & 99 & Cohen kappa statistic & 0.738 & 0.765 \\
\hline Calvete et al. [94], 2013 & ES & 89 & Cohen kappa statistic & 0.838 & - \\
\hline Cantisani et al. [88], 2014 & SR & 344 & Cohen kappa statistic & 0.95 & - \\
\hline Lim et al. [91], 2012 & $\mathrm{ECl}$ & 56 & Pearson correlation coefficient & $0.73,0.77,0.79$ & $0.73,0.84,0.87$ \\
\hline Cho et al. [17], 2017 & $\mathrm{ECl}$ & 173 & Intraclass correlation coefficient & 0.96 & $0.97,0.98$ \\
\hline Zhang et al. [21], 2012 & pSWE & 173 & Intraclass correlation coefficient & 0.86 & 0.90 \\
\hline Grazhdani et al. [95], 2014 & pSWE & 82 & Intraclass correlation coefficient & 0.75 & - \\
\hline Friedrich-Rust et al. [93], 2012 & pSWE & 56 & Spearman correlation coefficient & - & 0.82 \\
\hline Hofauer et al. [89], 2016 & pSWE & 10 & Intraclass correlation coefficient & 0.50 & $0.640,0.740$ \\
\hline Veyrieres et al. [44], 2012 & 2-D SWE & 102 & Intraclass correlation coefficient & 0.97 & - \\
\hline Zhou et al. [23], 2017 & 2-D SWE & 302 & Intraclass correlation coefficient & 0.813 & 0.905 \\
\hline
\end{tabular}

ES, elasticity score; SR, strain ratio; ECI, elasticity contrast index; pSWE, point shear-wave elastography; 2-D SWE, 2-dimensional shear-wave elastography. 
expected effect is not known $[13,14]$. Thus, elastography should be selectively used in TNs with calcifications and cystic changes.

\section{Nodule position}

Superficially located nodules are subject to the near-field artifact [49]. Deeply located nodules have been found to be affected by the stress or ARFI pulse decay phenomenon [4]. Isthmic nodules are difficult to evaluate, since they are compressed between the skin and the stiff trachea [49].

\section{Nodule size}

TNs larger than $3 \mathrm{~cm}$ in diameter may be unable to be adequately compressed by external compression elastography because of their deeper portions $[4,44]$.

\section{Experience of the Operator}

Several studies have investigated the reproducibility of elastography (Table 2) $[17,21,23,44,87-96]$. SWE often shows better reproducibility than SE. Manual external compression in SE leads to operator-dependent variability. Although SWE is less operatordependent, external pressure can affect SW propagation through insonated tissue [97] and operator error is the most common type source of artifacts in SWE [98]. Thus, US elastography should be performed by experienced operators using objective parameters with a quality indicator.

\section{Motion Artifacts (CA Pulsation)}

CA pulsation generates compression and decompression movements, inducing a certain degree of variable deformations that interfere in the elastographic evaluation. Longitudinal scans should be used because they are less susceptible to effects from the CA [99], but if SE with the CA is used, transverse scans should be employed $[4,15]$.

\section{Pathological Type of Thyroid Cancer}

SWS readings may be low in non-papillary thyroid carcinomas. Some articles about follicular and medullary carcinomas have stated that such tumors are soft and difficult to distinguish from benign TNs $[10,100]$.

\section{Summary and Future Directions}

US elastography examinations of the thyroid are easily integrated into conventional US examinations with many high-end systems. This procedure is completely painless for the patient, and only requires a few extra minutes, with no separate patient preparation.

US elastography has the potential to distinguish benign from malignant TNs, offering non-invasive complementary information to conventional US. The main role of US elastography is to indicate which nodules may be followed up without resorting to FNA or surgery because of its high NPV. It may be particularly useful in patients who have nondiagnostic or indeterminate FNA cytology results. US elastography might be used to guide the follow-up of lesions negative for malignancy at FNA.

Despite the initial optimism about this technique, less promising results are increasingly reported. Some authors even argued that "it [is] less likely that the use of this imaging technique to study TNs will expand significantly in the near future" [101]. Furthermore, some hold that the modulus estimates for the thyroid might be incorrect. Estimates of shear moduli based on SWS are highly dependent on boundary conditions (minimum 3-6 cm) that cannot be met in the thyroid gland. The thyroid is not homogeneous, which is another cause of inaccurate SWE measurements.

The heterogeneous results of available studies are in part due to selection bias (varying percentages of malignancy), small cohort size, and the use of non-uniform standardization of the technique (e.g., 4- or 5-point ES, stiffness index) and of the measurement method. The value of US elastography may be limited at institutions that show high diagnostic performance by highly dedicated physicians [62]. Studies have proposed many different cut-off values, but no meta-analyses have presented average values, and no large multicentric studies have been conducted. No method has yet been standardized for the measurement of thyroid lesion area. The role of US elastography in TNs with undefined cytology is inconsistent, and the specific role of elastography in reducing and avoiding FNA still needs future verification. Moreover, research data are still too limited to establish the definitive role of US elastography in diagnosing the various forms of thyroiditis and diffuse thyroid diseases.

The technology is still under development, and to gain widespread clinical application, further validation will be necessary, with large cohort and multi-center prospective studies with less pre-selection to evaluate different TN characteristics, uncommon pathologies, and reproducibility, with the ultimate goal of determining how US elastography can be integrated with conventional US into emerging malignant risk classification systems (e.g., TI-RADS). Moreover, standardization of US elastography techniques will be necessary $[24,102]$.

The role of US elastography should be explored in more specific target populations. In particular, the use of US elastography in hyperfunctional TNs, multinodular goiter, and in patients with previous radioiodine therapy or surgery has not been studied enough [103]. The role of US elastography in the management of PTMC still needs to be defined. It is not known to what extent this technology may aid in the management of positron emission tomography/ 
computed tomography (PET/CT)-positive thyroid incidentalomas $[104,105]$. The value of US elastography for treatment monitoring of TN during and after radiofrequency, microwave, or laser ablation has not been studied sufficiently [106-108]. The value of US elastography-guided FNA biopsy of TNs in reducing nondiagnostic results needs to be further evaluated [109].

Additionally, computer-aided diagnosis (CAD) systems have been described that use different textural features and machine learning algorithms for classification. These applications may avoid possible diagnostic errors and are able to simplify, formulate, and standardize TN classification systems [110]. More recently, deep learning has pervaded every aspect of medical image analysis. Compared with traditional machine learning methods, this method has the benefit of not requiring image feature identification and calculation as a first step; instead, features are identified as part of the learning process [111].

In terms of future directions of US elastography for the thyroid, it should improve the diagnostic performance of conventional US as a good adjunctive diagnostic tool [62]. Ideally, with advances in CAD systems and deep learning, the conventional US, US elastography, and PET/CT features of nodules could be analyzed automatically and converted into an estimate of its risk for malignancy.

ORCID: Chong-Ke Zhao: https://orcid.org/0000-0003-0968-4464; Hui-Xiong Xu: https://orcid.org/0000-0002-8699-854X

\section{Conflict of Interest}

No potential conflict of interest relevant to this article was reported.

\section{Acknowledgments}

This work was supported in part by the National Natural Science Foundation of China (grants 81671695, 81371570, and 81725008), Shanghai Hospital Development Center (grants 16CR3061B and SHDC12014229), and the Science and Technology Commission of Shanghai Municipality (grants 16411971100 and 14441900900).

\section{References}

1. Ophir J, Cespedes I, Ponnekanti H, Yazdi Y, Li X. Elastography: a quantitative method for imaging the elasticity of biological tissues. Ultrason Imaging 1991;13:111-134.

2. Lyshchik A, Higashi T, Asato R, Tanaka S, Ito J, Mai JJ, et al. Thyroid gland tumor diagnosis at US elastography. Radiology 2005;237:202-211.

3. Sebag F, Vaillant-Lombard J, Berbis J, Griset V, Henry JF, Petit P, et al. Shear wave elastography: a new ultrasound imaging mode for the differential diagnosis of benign and malignant thyroid nodules. J
Clin Endocrinol Metab 2010;95:5281-5288.

4. Cosgrove D, Barr R, Bojunga J, Cantisani V, Chammas MC, Dighe M, et al. WFUMB guidelines and recommendations on the clinical use of ultrasound elastography: part 4. Thyroid. Ultrasound Med Biol 2017:43:4-26.

5. Haugen BR, Alexander EK, Bible KC, Doherty GM, Mandel SJ, Nikiforov YE, et al. 2015 American Thyroid Association management guidelines for adult patients with thyroid nodules and differentiated thyroid cancer: the American Thyroid Association Guidelines Task Force on Thyroid Nodules and Differentiated Thyroid Cancer. Thyroid 2016;26:1-133.

6. Gharib H, Papini E, Garber JR, Duick DS, Harrell RM, Hegedus L, et al. American Association of Clinical Endocrinologists, American College of Endocrinology, and Associazione Medici Endocrinologi Medical guidelines for clinical practice for the diagnosis and management of thyroid nodules: 2016 update. Endocr Pract 2016;22:622-639.

7. Cosgrove D, Piscaglia F, Bamber J, Bojunga J, Correas JM, Gilja $\mathrm{OH}$, et al. EFSUMB guidelines and recommendations on the clinical use of ultrasound elastography. Part 2: Clinical applications. Ultraschall Med 2013;34:238-253.

8. Bamber J, Cosgrove D, Dietrich CF, Fromageau J, Bojunga J, Calliada $F$, et al. EFSUMB guidelines and recommendations on the clinical use of ultrasound elastography. Part 1: Basic principles and technology. Ultraschall Med 2013;34:169-184.

9. Shiina T, Nightingale KR, Palmeri ML, Hall TJ, Bamber JC, Barr RG, et al. WFUMB guidelines and recommendations for clinical use of ultrasound elastography: Part 1: basic principles and terminology. Ultrasound Med Biol 2015:41:1126-1147.

10. Andrioli M, Persani L. Elastographic techniques of thyroid gland: current status. Endocrine 2014;46:455-461.

11. Asteria C, Giovanardi A, Pizzocaro A, Cozzaglio L, Morabito A, Somalvico $F$, et al. US-elastography in the differential diagnosis of benign and malignant thyroid nodules. Thyroid 2008;18:523-531.

12. Trimboli P, Guglielmi R, Monti S, Misischi I, Graziano F, Nasrollah $\mathrm{N}$, et al. Ultrasound sensitivity for thyroid malignancy is increased by real-time elastography: a prospective multicenter study. J Clin Endocrinol Metab 2012;97:4524-4530.

13. Rago T, Santini F, Scutari M, Pinchera A, Vitti P. Elastography: new developments in ultrasound for predicting malignancy in thyroid nodules. J Clin Endocrinol Metab 2007;92:2917-2922.

14. Cantisani V, Lodise P, Grazhdani H, Mancuso E, Maggini E, Di Rocco $\mathrm{G}$, et al. Ultrasound elastography in the evaluation of thyroid pathology: current status. Eur J Radiol 2014;83:420-428.

15. Dighe M, Bae U, Richardson ML, Dubinsky TJ, Minoshima S, Kim Y. Differential diagnosis of thyroid nodules with US elastography using carotid artery pulsation. Radiology 2008;248:662-669.

16. Dighe M, Luo S, Cuevas C, Kim Y. Efficacy of thyroid ultrasound elastography in differential diagnosis of small thyroid nodules. Eur $」$ 
Radiol 2013;82:e274-e280.

17. Cho YJ, Ha EJ, Han M, Choi JW. US elastography using carotid artery pulsation may increase the diagnostic accuracy for thyroid nodules with US-pathology discordance. Ultrasound Med Biol 2017;43:1587-1595.

18. Zhang YF, He Y, Xu HX, Xu XH, Liu C, Guo LH, et al. Virtual touch tissue imaging on acoustic radiation force impulse elastography: a new technique for differential diagnosis between benign and malignant thyroid nodules. J Ultrasound Med 2014;33:585-595.

19. Xu JM, Xu XH, Xu HX, Zhang YF, Zhang J, Guo LH, et al. Conventional US, US elasticity imaging, and acoustic radiation force impulse imaging for prediction of malignancy in thyroid nodules. Radiology 2014;272:577-586.

20. Xu JM, Xu HX, Zhang YF, Guo LH, Liu LN, Bo XW, et al. Virtual touch tissue imaging for differential diagnosis of thyroid nodules: additional value of the area ratio. J Ultrasound Med 2016;35:917926.

21. Zhang YF, Xu HX, He Y, Liu C, Guo LH, Liu LN, et al. Virtual touch tissue quantification of acoustic radiation force impulse: a new ultrasound elastic imaging in the diagnosis of thyroid nodules. PLoS One 2012;7:e49094.

22. Bojunga J, Dauth N, Berner C, Meyer G, Holzer K, Voelkl L, et al. Acoustic radiation force impulse imaging for differentiation of thyroid nodules. PLoS One 2012;7:e42735.

23. Zhou $H$, Zhou XL, Xu HX, Li DD, Liu BJ, Zhang YF, et al. Virtual touch tissue imaging and quantification in the evaluation of thyroid nodules. J Ultrasound Med 2017;36:251-260.

24. Mao F, Xu HX, Zhou H, Bo XW, Li XL, Li DD, et al. Assessment of virtual touch tissue imaging quantification and the ultrasound thyroid imaging reporting and data system in patients with thyroid nodules referred for biopsy. J Ultrasound Med 2018;37:725-736.

25. He YP, Xu HX, Li XL, Li DD, Bo XW, Zhao CK, et al. Comparison of Virtual Touch Tissue Imaging \& Quantification (VTIQ) and Toshiba shear wave elastography (T-SWE) in diagnosis of thyroid nodules: Initial experience. Clin Hemorheol Microcirc 2017;66:15-26.

26. He YP, Xu HX, Wang D, Li XL, Ren WW, Zhao CK, et al. First experience of comparisons between two different shear wave speed imaging systems in differentiating malignant from benign thyroid nodules. Clin Hemorheol Microcirc 2017;65:349-361.

27. Park AY, Son EJ, Han K, Youk JH, Kim JA, Park CS. Shear wave elastography of thyroid nodules for the prediction of malignancy in a large scale study. Eur J Radiol 2015;84:407-412.

28. Liu BX, Xie XY, Liang JY, Zheng YL, Huang GL, Zhou LY, et al. Shear wave elastography versus real-time elastography on evaluation thyroid nodules: a preliminary study. Eur J Radiol 2014;83:11351143.

29. Mehrmohammadi M, Song P, Meixner DD, Fazzio RT, Chen S, Greenleaf JF, et al. Comb-push ultrasound shear elastography (CUSE) for evaluation of thyroid nodules: preliminary in vivo results.
IEEE Trans Med Imaging 2015;34:97-106.

30. Gregory A, Bayat M, Kumar V, Denis M, Kim BH, Webb J, et al. Differentiation of benign and malignant thyroid nodules by using comb-push ultrasound shear elastography: a preliminary two-plane view study. Acad Radiol 2018;25:1388-1397.

31. Zhao CK, Chen SG, Alizad A, He YP, Wang Q, Wang D, et al. Threedimensional shear wave elastography for differentiating benign from malignant thyroid nodules. J Ultrasound Med 2018;37:17771788.

32. Liu BJ, Li DD, Xu HX, Guo LH, Zhang YF, Xu JM, et al. Quantitative shear wave velocity measurement on acoustic radiation force impulse elastography for differential diagnosis between benign and malignant thyroid nodules: a meta-analysis. Ultrasound Med Biol 2015;41:3035-3043.

33. Friedrich-Rust M, Vorlaender C, Dietrich CF, Kratzer W, Blank W, Schuler $A$, et al. Evaluation of strain elastography for differentiation of thyroid nodules: results of a prospective DEGUM multicenter study. Ultraschall Med 2016;37:262-270.

34. Lin $P$, Chen M, Liu B, Wang S, Li X. Diagnostic performance of shear wave elastography in the identification of malignant thyroid nodules: a meta-analysis. Eur Radiol 2014;24:2729-2738.

35. Sun J, Cai J, Wang X. Real-time ultrasound elastography for differentiation of benign and malignant thyroid nodules: a metaanalysis. J Ultrasound Med 2014;33:495-502.

36. Moon HJ, Sung JM, Kim EK, Yoon JH, Youk JH, Kwak JY. Diagnostic performance of gray-scale US and elastography in solid thyroid nodules. Radiology 2012;262:1002-1013.

37. Hu X, Liu Y, Qian L. Diagnostic potential of real-time elastography (RTE) and shear wave elastography (SWE) to differentiate benign and malignant thyroid nodules: a systematic review and metaanalysis. Medicine (Baltimore) 2017;96:e8282.

38. Razavi SA, Hadduck TA, Sadigh G, Dwamena BA. Comparative effectiveness of elastographic and B-mode ultrasound criteria for diagnostic discrimination of thyroid nodules: a meta-analysis. AJR Am J Roentgenol 2013;200:1317-1326.

39. Dobruch-Sobczak K, Zalewska EB, Guminska A, Slapa RZ, Mlosek K, Wareluk $P$, et al. Diagnostic performance of shear wave elastography parameters alone and in combination with conventional B-mode ultrasound parameters for the characterization of thyroid nodules: a prospective, dual-center study. Ultrasound Med Biol 2016;42:2803-2811.

40. Unluturk U, Erdogan MF, Demir O, Gullu S, Baskal N. Ultrasound elastography is not superior to grayscale ultrasound in predicting malignancy in thyroid nodules. Thyroid 2012;22:1031-1038.

41. Ghajarzadeh M, Sodagari F, Shakiba M. Diagnostic accuracy of sonoelastography in detecting malignant thyroid nodules: a systematic review and meta-analysis. AJR Am J Roentgenol 2014;202:W379-W389.

42. Dong FJ, Li M, Jiao $Y, X u J F$, Xiong $Y$, Zhang $L$, et al. Acoustic 
radiation force impulse imaging for detecting thyroid nodules: a systematic review and pooled meta-analysis. Med Ultrason 2015;17:192-199.

43. Zhan J, Jin JM, Diao XH, Chen Y. Acoustic radiation force impulse imaging (ARFI) for differentiation of benign and malignant thyroid nodules: a meta-analysis. Eur J Radiol 2015;84:2181-2186.

44. Veyrieres JB, Albarel F, Lombard JV, Berbis J, Sebag F, Oliver C, et al. A threshold value in shear wave elastography to rule out malignant thyroid nodules: a reality? Eur J Radiol 2012;81:3965-3972.

45. Azizi G, Keller JM, Mayo ML, Piper K, Puett D, Earp KM, et al. Thyroid nodules and shear wave elastography: a new tool in thyroid cancer detection. Ultrasound Med Biol 2015;41:2855-2865.

46. Kim H, Kim JA, Son EJ, Youk JH. Quantitative assessment of shearwave ultrasound elastography in thyroid nodules: diagnostic performance for predicting malignancy. Eur Radiol 2013;23:25322537.

47. Bojunga J, Herrmann E, Meyer G, Weber S, Zeuzem S, Friedrich-Rust M. Real-time elastography for the differentiation of benign and malignant thyroid nodules: a meta-analysis. Thyroid 2010;20:11451150.

48. Wang H, Zhao L, Xin X, Wei X, Zhang S, Li Y, et al. Diagnostic value of elastosonography for thyroid microcarcinoma. Ultrasonics 2014;54:1945-1949.

49. Wang Y, Dan HJ, Dan HY, Li T, Hu B. Differential diagnosis of small single solid thyroid nodules using real-time ultrasound elastography. J Int Med Res 2010;38:466-472.

50. Ma HJ, Yang JC, Leng ZP, Chang Y, Kang H, Teng LH. Preoperative prediction of papillary thyroid microcarcinoma via multiparameter ultrasound. Acta Radiol 2017;58:1303-1311.

51. Zhang YF, Liu C, Xu HX, Xu JM, Zhang J, Guo LH, et al. Acoustic radiation force impulse imaging: a new tool for the diagnosis of papillary thyroid microcarcinoma. Biomed Res Int 2014;2014:416969.

52. Zhang YF, Xu HX, Xu JM, Liu C, Guo LH, Liu LN, et al. Acoustic radiation force impulse elastography in the diagnosis of thyroid nodules: useful or not useful? Ultrasound Med Biol 2015;41:25812593.

53. Duan SB, Yu J, Li X, Han ZY, Zhai HY, Liang P. Diagnostic value of two-dimensional shear wave elastography in papillary thyroid microcarcinoma. Onco Targets Ther 2016;9:1311-1317.

54. Ruchala M, Szczepanek-Parulska E, Zybek A, Moczko J, Czarnywojtek A, Kaminski $G$, et al. The role of sonoelastography in acute, subacute and chronic thyroiditis: a novel application of the method. Eur J Endocrinol 2012;166:425-432.

55. Sporea I, Vlad M, Bota S, Sirli RL, Popescu A, Danila M, et al. Thyroid stiffness assessment by acoustic radiation force impulse elastography (ARFI). Ultraschall Med 2011;32:281-285.

56. Magri F, Chytiris S, Capelli V, Gaiti M, Zerbini F, Carrara R, et al. Comparison of elastographic strain index and thyroid fine-needle aspiration cytology in 631 thyroid nodules. J Clin Endocrinol Metab 2013:98:4790-4797.

57. Yildirim D, Gurses B, Gurpinar B, Ekci B, Colakoglu B, Kaur A. Nodule or pseudonodule? Differentiation in Hashimoto's thyroiditis with sonoelastography. J Int Med Res 2011;39:2360-2369.

58. Sahin M, Cakal E, Ozbek M, Gungunes A, Arslan MS, Akkaymak ET, et al. Elastography in the differential diagnosis of thyroid nodules in Hashimoto thyroiditis. Med Oncol 2014;31:97.

59. Liu BJ, Xu HX, Zhang YF, Xu JM, Li DD, Bo XW, et al. Acoustic radiation force impulse elastography for differentiation of benign and malignant thyroid nodules with concurrent Hashimoto's thyroiditis. Med Oncol 2015;32:50.

60. Dighe M, Kim J, Luo S, Kim Y. Utility of the ultrasound elastographic systolic thyroid stiffness index in reducing fine-needle aspirations. $J$ Ultrasound Med 2010;29:565-574.

61. Russ G, Royer B, Bigorgne C, Rouxel A, Bienvenu-Perrard M, Leenhardt $L$. Prospective evaluation of thyroid imaging reporting and data system on 4550 nodules with and without elastography. Eur J Endocrinol 2013;168:649-655.

62. Kwak JY, Kim EK. Ultrasound elastography for thyroid nodules: recent advances. Ultrasonography 2014;33:75-82.

63. Cappelli C, Pirola I, Gandossi E, Agosti B, Cimino E, Casella C, et al. Real-time elastography: a useful tool for predicting malignancy in thyroid nodules with nondiagnostic cytologic findings. J Ultrasound Med 2012;31:1777-1782.

64. Rago T, Scutari M, Santini F, Loiacono V, Piaggi P, Di Coscio G, et al. Real-time elastosonography: useful tool for refining the presurgical diagnosis in thyroid nodules with indeterminate or nondiagnostic cytology. J Clin Endocrinol Metab 2010;95:5274-5280.

65. Cantisani V, Ulisse S, Guaitoli E, De Vito C, Caruso R, Mocini R, et al. Q-elastography in the presurgical diagnosis of thyroid nodules with indeterminate cytology. PLoS One 2012;7:e50725.

66. Lippolis PV, Tognini S, Materazzi G, Polini A, Mancini R, Ambrosini $C E$, et al. Is elastography actually useful in the presurgical selection of thyroid nodules with indeterminate cytology? I Clin Endocrinol Metab 2011;96:E1826-E1830.

67. Trimboli P, Treglia G, Sadeghi R, Romanelli F, Giovanella L. Reliability of real-time elastography to diagnose thyroid nodules previously read at FNAC as indeterminate: a meta-analysis. Endocrine 2015;50:335-343.

68. Samir AE, Dhyani M, Anvari A, Prescott J, Halpern EF, Faquin WC, et al. Shear-wave elastography for the preoperative risk stratification of follicular-patterned lesions of the thyroid: diagnostic accuracy and optimal measurement plane. Radiology 2015;277:565-573.

69. Azizi G, Keller JM, Mayo ML, Piper K, Puett D, Earp KM, et al. Shear wave elastography and Afirma gene expression classifier in thyroid nodules with indeterminate cytology: a comparison study. Endocrine 2018;59:573-584.

70. Bardet S, Ciappuccini R, Pellot-Barakat C, Monpeyssen H, Michels 
$\mathrm{JJ}$, Tissier F, et al. Shear wave elastography in thyroid nodules with indeterminate cytology: results of a prospective bicentric study. Thyroid 2017;27:1441-1449.

71. Lin $K$, Xiang Y, Qiao L, Liu R, Dong S, Zhang X. A predictive model for selecting malignant thyroid nodules in patients with nondiagnostic or indeterminate fine-needle aspiration cytologic findings. J Ultrasound Med 2015;34:1245-1251.

72. Park VY, Kim EK, Kwak JY, Yoon JH, Kim MJ, Moon HJ. Thyroid imaging reporting and data system and ultrasound elastography: diagnostic accuracy as a tool in recommending repeat fine-needle aspiration for solid thyroid nodules with non-diagnostic fine-needle aspiration cytology. Ultrasound Med Biol 2016;42:399-406.

73. Samir AE. The role and value of ultrasound elastography in the evaluation of thyroid nodules. Cancer Cytopathol 2016;124:765766.

74. Anvari A, Dhyani M, Stephen AE, Samir AE. Reliability of shear-wave elastography estimates of the young modulus of tissue in follicular thyroid neoplasms. AJR Am J Roentgenol 2016;206:609-616.

75. Xu JM, Xu XH, Xu HX, Zhang YF, Guo LH, Liu LN, et al. Prediction of cervical lymph node metastasis in patients with papillary thyroid cancer using combined conventional ultrasound, strain elastography, and acoustic radiation force impulse (ARFI) elastography. Eur Radiol 2016;26:2611-2622.

76. Park AY, Kim JA, Son EJ, Youk JH. Shear-wave elastography for papillary thyroid carcinoma can improve prediction of cervical lymph node metastasis. Ann Surg Oncol 2016;23:722-729.

77. Yoon HY, Lee JH, Kim YE, Kim EK, Moon HJ, Yoon JH, et al. Clinical significance of histogram parameters on elastography in patients with papillary thyroid microcarcinomas. Ultrasound Q 2017;33:219224.

78. Sporea I, Sirli R, Bota S, Vlad M, Popescu A, Zosin I. ARFI elastography for the evaluation of diffuse thyroid gland pathology: preliminary results. World J Radiol 2012;4:174-178.

79. Liu J, Zhang Y, Ji Y, Wan Q, Dun G. The value of shear wave elastography in diffuse thyroid disease. Clin Imaging 2018;49:187192.

80. Fukuhara T, Matsuda E, Endo Y, Takenobu M, Izawa S, Fujiwara K, et al. Correlation between quantitative shear wave elastography and pathologic structures of thyroid lesions. Ultrasound Med Biol 2015;41:2326-2332.

81. Yang Z, Zhang H, Wang K, Cui G, Fu F. Assessment of diffuse thyroid disease by strain ratio in ultrasound elastography. Ultrasound Med Biol 2015;41:2884-2889.

82. Xie P, Xiao Y, Liu F. Real-time ultrasound elastography in the diagnosis and differential diagnosis of subacute thyroiditis. J Clin Ultrasound 2011;39:435-440.

83. Slman R, Monpeyssen H, Desarnaud S, Haroche J, Fediaevsky Ldu P, Fabrice $M$, et al. Ultrasound, elastography, and fluorodeoxyglucose positron emission tomography/computed tomography imaging in
Riedel's thyroiditis: report of two cases. Thyroid 2011;21:799-804.

84. Ning CP, Jiang SQ, Zhang T, Sun LT, Liu YJ, Tian JW. The value of strain ratio in differential diagnosis of thyroid solid nodules. Eur J Radiol 2012;81:286-291.

85. Yang YP, Xu XH, Bo XW, Liu BJ, Guo LH, Xu JM, et al. Comparison of virtual touch tissue imaging \& quantification (VTIQ) and virtual touch tissue quantification (VTQ) for diagnosis of thyroid nodules. Clin Hemorheol Microcirc 2017;65:137-149.

86. Sun $C Y$, Lei $K R$, Liu BJ, Bo XW, Li XL, He YP, et al. Virtual touch tissue imaging and quantification (VTIQ) in the evaluation of thyroid nodules: the associated factors leading to misdiagnosis. Sci Rep 2017;7:41958.

87. Ragazzoni F, Deandrea M, Mormile A, Ramunni MJ, Garino F, Magliona G, et al. High diagnostic accuracy and interobserver reliability of real-time elastography in the evaluation of thyroid nodules. Ultrasound Med Biol 2012;38:1154-1162.

88. Cantisani V, Grazhdani H, Ricci P, Mortele K, Di Segni M, D'Andrea $V$, et al. Q-elastosonography of solid thyroid nodules: assessment of diagnostic efficacy and interobserver variability in a large patient cohort. Eur Radiol 2014;24:143-150.

89. Hofauer B, Mansour N, Heiser C, Wirth M, Strassen U, Loeffelbein $D$, et al. Reproducibility of acoustic radiation force impulse imaging in thyroid and salivary glands with experienced and inexperienced examiners. Ultrasound Med Biol 2016;42:2545-2552.

90. Park SH, Kim SJ, Kim EK, Kim MJ, Son EJ, Kwak JY. Interobserver agreement in assessing the sonographic and elastographic features of malignant thyroid nodules. AJR Am J Roentgenol 2009;193:W416-W423.

91. Lim DJ, Luo S, Kim MH, Ko SH, Kim Y. Interobserver agreement and intraobserver reproducibility in thyroid ultrasound elastography. AJR Am J Roentgenol 2012;198:896-901.

92. Kim JK, Baek JH, Lee JH, Kim JL, Ha EJ, Kim TY, et al. Ultrasound elastography for thyroid nodules: a reliable study? Ultrasound Med Biol 2012;38:1508-1513.

93. Friedrich-Rust M, Romenski O, Meyer G, Dauth N, Holzer K, Grunwald $F$, et al. Acoustic radiation force impulse-imaging for the evaluation of the thyroid gland: a limited patient feasibility study. Ultrasonics 2012;52:69-74.

94. Calvete AC, Rodriguez JM, de Dios Berna-Mestre J, Rios A, AbellanRivero D, Reus M. Interobserver agreement for thyroid elastography: value of the quality factor. J Ultrasound Med 2013;32:495-504.

95. Grazhdani H, Cantisani V, Lodise P, Di Rocco G, Proietto MC, Fioravanti $E$, et al. Prospective evaluation of acoustic radiation force impulse technology in the differentiation of thyroid nodules: accuracy and interobserver variability assessment. J Ultrasound 2014;17:13-20.

96. Swan KZ, Nielsen VE, Bibby BM, Bonnema SJ. Is the reproducibility of shear wave elastography of thyroid nodules high enough for clinical use? A methodological study. Clin Endocrinol (Oxf) 
2017;86:606-613.

97. Lam AC, Pang SW, Ahuja AT, Bhatia KS. The influence of precompression on elasticity of thyroid nodules estimated by ultrasound shear wave elastography. Eur Radiol 2016;26:28452852.

98. Dighe $M$, Hippe DS, Thiel J. Artifacts in shear wave elastography images of thyroid nodules. Ultrasound Med Biol 2018;44:11701176.

99. Oliver C, Vaillant-Lombard J, Albarel F, Berbis J, Veyrieres JB, Sebag $F$, et al. What is the contribution of elastography to thyroid nodules evaluation? Ann Endocrinol (Paris) 2011;72:120-124.

100. Andrioli M, Trimboli P, Amendola S, Valabrega S, Fukunari N, Mirella $M$, et al. Elastographic presentation of medullary thyroid carcinoma. Endocrine 2014;45:153-155.

101. Rivo-Vazquez A, Rodriguez-Lorenzo A, Rivo-Vazquez JE, ParamoFernandez C, Garcia-Lorenzo F, Pardellas-Rivera H, et al. The use of ultrasound elastography in the assessment of malignancy risk in thyroid nodules and multinodular goitres. Clin Endocrinol (Oxf) 2013;79:887-891.

102. Schenke S, Zimny M. Combination of sonoelastography and TIRADS for the diagnostic assessment of thyroid nodules. Ultrasound Med Biol 2018;44:575-583.

103. Trimboli P, Paone G, Zatelli MC, Ceriani L, Giovanella L. Realtime elastography in autonomously functioning thyroid nodules: relationship with TSH levels, scintigraphy, and ultrasound patterns. Endocrine 2017;58:488-494.

104. Hegedus L. Can elastography stretch our understanding of thyroid histomorphology? J Clin Endocrinol Metab 2010;95:5213-5215.
105. Demir O, Kose N, Ozkan E, Unluturk U, Aras G, Erdogan MF. Clinical significance of thyroid incidentalomas identified by 18F-FDG PET/CT: correlation of ultrasonograpy findings with cytology results. Nucl Med Commun 2016;37:715-720.

106. Idiz UO, Aysan E, Elmas L, Yildiz S, Akbulut H. The place of elastography in evaluating the efficacy of radiofrequency ablation of thyroid nodules. Am Surg 2017;83:1228-1234.

107. Andrioli M, Valcavi R. The peculiar ultrasonographic and elastographic features of thyroid nodules after treatment with laser or radiofrequency: similarities and differences. Endocrine 2014;47:967-968.

108. Korkusuz H, Happel C, Klebe J, Ackermann H, Grunwald F. Diagnostic accuracy of elastography and scintigraphic imaging after thermal microwave ablation of thyroid nodules. Rofo 2015; 187:353-359.

109. Yildirim D, Gurses B, Gurpinar B, Ekci B, Colakoglu B, Sahin M, et al. The value of ultrasound elastography-guided fine-needle aspiration biopsy of thyroid nodules in reducing nondiagnostic results. J Med Ultrason (2001) 2013;40:169-174.

110. Choi YJ, Baek JH, Park HS, Shim WH, Kim TY, Shong YK, et al. A computer-aided diagnosis system using artificial intelligence for the diagnosis and characterization of thyroid nodules on ultrasound: initial clinical assessment. Thyroid 2017;27:546-552.

111. Sollini M, Cozzi L, Chiti A, Kirienko M. Texture analysis and machine learning to characterize suspected thyroid nodules and differentiated thyroid cancer: Where do we stand? Eur J Radiol 2018;99:1-8. 